\title{
NF-KB is essential for epithelial- mesenchymal transition and metastasis in a model of breast cancer progression
}

\author{
Margit A. Huber, ${ }^{1,2,3}$ Ninel Azoitei, ${ }^{1}$ Bernd Baumann, ${ }^{1}$ Stefan Grünert, ${ }^{2}$ Andreas Sommer, ${ }^{2}$ \\ Hubert Pehamberger, ${ }^{3}$ Norbert Kraut, ${ }^{4}$ Hartmut Beug, ${ }^{2}$ and Thomas Wirth ${ }^{1}$
}

1Department of Physiological Chemistry, Ulm University, Ulm, Germany. 2Institute of Molecular Pathology, Vienna, Austria. ${ }^{3}$ Department of Dermatology, Vienna Medical University, Vienna, Austria. ${ }^{4}$ Department of New Chemical Entity Lead Discovery, Boehringer Ingelheim Austria GmbH, Vienna, Austria.

\begin{abstract}
The transcription factor NF- $\kappa B$ is activated in a range of human cancers and is thought to promote tumorigenesis, mainly due to its ability to protect transformed cells from apoptosis. To investigate the role of NF- $\kappa B$ in epithelial plasticity and metastasis, we utilized a well-characterized in vitro/in vivo model of mammary carcinogenesis that depends on the collaboration of the Ha-Ras oncoprotein and TGF- $\beta$. We show here that the IKK-2/I $\kappa B \alpha / N F-\kappa B$ pathway is required for the induction and maintenance of epithelial-mesenchymal transition (EMT). Inhibition of NF- $\kappa$ B signaling prevented EMT in Ras-transformed epithelial cells, while activation of this pathway promoted the transition to a mesenchymal phenotype even in the absence of TGF- $\beta$. Furthermore, inhibition of NF- $\kappa B$ activity in mesenchymal cells caused a reversal of EMT, suggesting that $N F-\kappa B$ is essential for both the induction and maintenance of EMT. In line with the importance of EMT for invasion, blocking of NF- $\kappa B$ activity abrogated the metastatic potential of mammary epithelial cells in a mouse model system. Collectively, these data provide evidence of an essential role for NF- $\kappa B$ during distinct steps of breast cancer progression and suggest that the cooperation of Ras- and TGF- $\beta$-dependent signaling pathways in late-stage tumorigenesis depends critically on NF- $\mathrm{B}$ activity.
\end{abstract}

\section{Introduction}

Cancer development and metastasis are multistep processes that involve local tumor growth and invasion followed by dissemination to and re-establishment at distant sites. The ability of a tumor to metastasize is the major determinant of the mortality of cancer patients. Thus, elucidating the molecular pathways essential for tumor metastasis is of high priority in cancer biology and provides a basis for novel therapeutic targets for the development of antimetastatic cancer treatments.

Initially discovered and studied as a major activator of immune and inflammatory functions via its ability to induce expression of genes encoding cytokines, cytokine receptors, and cell-adhesion molecules, the transcription factor NF- $\mathrm{B}$ has recently been implicated in the control of cell proliferation and oncogenesis (reviewed in ref. 1). NF- $\mathrm{KB}$ transcription factors bind to DNA as hetero- or homodimers that are composed of five possible subunits in mouse and human (RelA/p65, c-Rel, RelB, p50, and p52). These proteins are characterized by their Rel homology domains, which mediate DNA binding, dimerization, and interactions with inhibitory factors known as inhibitor $\kappa \mathrm{B}(\mathrm{I} \kappa \mathrm{B})$ proteins. Whereas the Rel/p65 and p50 subunits are ubiquitously expressed, the p52, c-Rel, and RelB subunits are more functionally important in specific differentiated cell types (reviewed in ref. 2). In most unstimulated cells, NF-кB dimers are inactive because of association with $\mathrm{I} \kappa \mathrm{B}$ proteins that mask the

Nonstandard abbreviations used: benzyloxycarbonyl-Val-Ala-Asp-fluoromethylketone (Z-VAD-FMK); constitutively active (CA); electrophoretic mobility-shift assay (EMSA); epithelial-mesenchymal transition (EMT); IкB kinase (IKK); inhibitor $\kappa \mathrm{B}$

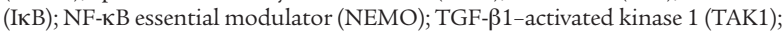
trans-dominant (TD).

Conflict of interest: The authors have declared that no conflict of interest exists.

Citation for this article: J. Clin. Invest. 114:569-581 (2004)

doi:10.1172/JCI200421358 nuclear localization sequence of NF- $\kappa \mathrm{B}$, thereby retaining it in the cytoplasm and preventing DNA binding. Several IкB proteins are

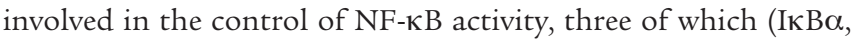
$\mathrm{I} \kappa \mathrm{B} \beta$, and $\mathrm{I} \kappa \mathrm{B} \varepsilon$ ) act as negative regulators in a stimulus-dependent manner. Stimulation of cells, for example, by proinflammatory cytokines such as TNF- $\alpha$ and IL-1, results in the phosphorylation of $\mathrm{I} \kappa \mathrm{B}$ at two serine residues located within the $\mathrm{N}$-terminal domain of the proteins (reviewed in refs. 3, 4). This phosphorylation of IкB results in ubiquitination of nearby lysine residues, which represents the signal for degradation by the $26 \mathrm{~S}$ proteasome. Degradation of the IкB proteins results in the liberation of NF- $\kappa \mathrm{B}$, allowing nuclear translocation and binding to cognate DNA motifs in the regulatory regions of a host of target genes. As a consequence, transcription of these genes, which are involved in immune and inflammatory responses and regulation of apoptosis, as well as in cell growth control, is induced (reviewed in refs. 3, 4). The critical step in NF-кB activation is the phosphorylation of I $\mathrm{B}$ by a high-molecular-weight IKB kinase (IKK) complex. This complex consists of two kinase proteins, IKK- 1 and IKK-2, (also called IKK- $\alpha$ and IKK- $\beta$, respectively), as well as a regulatory component called NF- $\mathrm{KB}$ essential modulator (NEMO; also called IKK- $\gamma$ ) (reviewed in ref. 4).

Ample evidence linking NF-кB activity to oncogenesis has accumulated in the past years (reviewed in refs. 1,2). A link between aberrant NF- $\mathrm{KB}$ activity and cancer was initially suggested by the identification of v-Rel, a viral homolog of c-Rel, as the transforming oncogene of an avian retrovirus that causes aggressive tumors in chickens (5). Moreover, oncogenic viruses, such as human $\mathrm{T}$ cell leukemia virus I or Epstein-Barr virus, activate NF- $\mathrm{BB}$ as part of the transformation process $(6,7)$. Translocation of the NF- $\kappa B$ gene $N F-\kappa B 2 / p 52$ and the IкB family member $B c l-3$ was observed in some lymphoid neoplasms (reviewed in ref. 8). High levels of $\mathrm{NF}-\kappa \mathrm{B}$ were shown to be essential for the transformed phenotype 
A

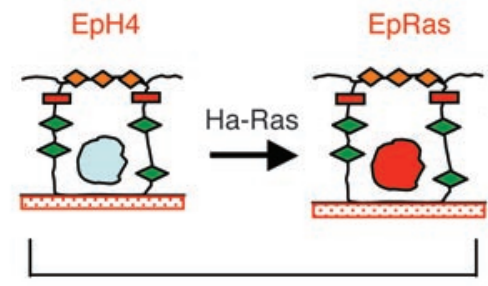

Polarized epithelial cells

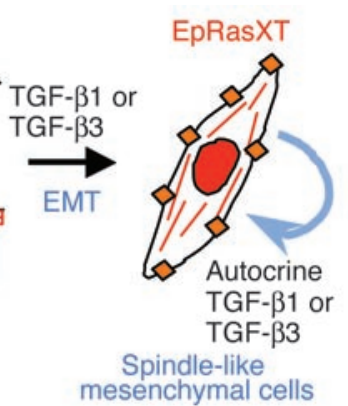

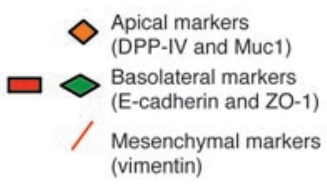

(vimentin)
B

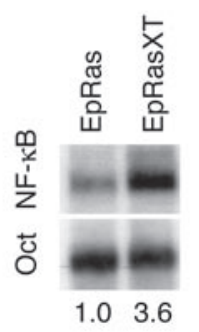

Figure 1

NF-кB activity is induced during EMT. (A) Schematic illustrates the morphology and epithelial/mesenchymal marker redistribution or expression found in the cell types used in our study. Nontransformed EpH4 mammary epithelial cells were stably transfected with the Ha-Ras oncogene to yield transformed epithelial EpRas cells that undergo EMT upon treatment with TGF- $\beta$, resulting in mesenchymal EpRasXT cells further stabilized by an autocrine TGF- $\beta$ loop. DPP-IV, dipeptidyl peptidase IV; ZO-1, zona occludens 1 . (B) EMSAs of whole-cell extracts (6 $\mu \mathrm{g})$ of exponentially growing EpRas and EpRasXT cells were performed with an NF-кB-specific probe (upper panel) and with an octamer-specific probe (Oct; lower panel) used as a control. Quantified relative DNA-binding levels are indicated below the EMSAs. Similar data were obtained using different protein extract preparations (see also Figure $2 \mathrm{~A}$ ).

of Hodgkin lymphoma tumor cells (9), and mutations in the gene encoding IкB $\alpha$ have been detected in some cases of Hodgkin lymphoma (10). Constitutive nuclear NF-кB activity, meanwhile, has emerged as a hallmark for many other human leukemias, lymphomas, and solid tumors (reviewed in refs. 2, 8). Furthermore, several oncoproteins, including $\mathrm{Ha}-\mathrm{Ras}$ and $\mathrm{Bcr}-\mathrm{Abl}$, are known to activate $\mathrm{NF}-\kappa \mathrm{B}$ and rely on NF- $\mathrm{KB}$ to mediate their transforming activity (reviewed in ref. 1). Although the exact role of NF-kB in the pathogenesis of human tumors remains to be determined, suppression of apoptosis is clearly of major importance, since inhibition of NF-кB sensitizes many tumor cells to death-inducing stimuli, including chemotherapeutic agents (reviewed in refs. 1,2).

Whether and how NF-кB also regulates invasive responses such as epithelial-mesenchymal transition (EMT) and metastasis is only poorly understood. Evidence has accumulated showing that EMT represents an important in vitro correlate of latestage tumor progression (11-15). As originally defined (16), EMT involves dedifferentiation of epithelial cells to fibroblastoid, migratory, and more malignant cells, showing a profoundly altered, mesenchymal gene expression program $(17,18)$. EMT also occurs during embryonic development and is regulated by an elaborate interplay of signaling pathways $(12,13,15$, 16). In several epithelial cell models, including EpH4 mammary epithelial cells, oncogenic Ras protects cells from TGF- $\beta$-induced cell cycle arrest and apoptosis, thus overcoming the tumor-suppressive effects of TGF- $\beta$ in early tumorigenesis. Furthermore, oncogenic Ras cooperates with TGF- $\beta$ to induce EMT, a phenotype that is stabilized by autocrine production of TGF- $\beta$ (19-23) and leads to cell migration and motility, which are crucial for tumor progression and metastasis (reviewed in ref. 15). The Ras downstream effector pathway required for EMT and metastasis was recently identified as the Raf/MEK/MAPK pathway, while hyperactive PI3K/Akt signaling enabled protection from TGF- $\beta$-induced apoptosis (17). In these model systems, metastatic potential strictly correlated with the ability of epithelial tumor cells to undergo EMT (15).

In this study, we show that NF-кB plays an essential role in the induction of EMT in Ras-transformed mammary epithelial cells. Loss of NF- $\kappa \mathrm{B}$ activity abrogated protection of these cells from TGF- $\beta$-induced apoptosis, but also actively suppressed an EMT gene program, thus blocking EMT. In contrast, gain of NF-кB activity induced EMT in these Ras-transformed cells in the absence of TGF- $\beta$. Moreover, NF-кB also plays an essential role in maintaining the mesenchymal state subsequent to EMT, as its inhibition caused reversal of EMT. In mice, inhibition of NF-KB activity strongly reduced the metastatic potential of Ras-transformed EpH4 cells. Our results indicate that NF- $\kappa B$ signaling is essential for EMT and metastasis in this murine mammary carcinoma model and suggest that therapeutic inhibition of NF- $\mathrm{KB}$ may be a useful strategy for the control of tumor invasion and metastasis.
Table 1

NF-кB-regulated genes induced during EMT in the EpRas/EpRasXT cell pair

\begin{tabular}{|c|c|c|c|}
\hline Gene name ${ }^{A}$ & Fold change ${ }^{B}$ & Category & Reference $^{C}$ \\
\hline Vimentin $^{\star}$ & 141.9 & Mesenchymal marker & 50 \\
\hline Placental proliferin 2 & 108.3 & Hormone & 51 \\
\hline Cholecystokinin ${ }^{\star}$ & 38.6 & Hormone & 52 \\
\hline$J E / M C P-1^{*}$ & 32.6 & Chemokine & 53 \\
\hline MMP-13 & 16.6 & Protease & 54 \\
\hline Tenascin- $C^{\star}$ & 11.0 & Mesenchymal marker & 55 \\
\hline Cathepsin B & 10.8 & Protease & 51 \\
\hline Stat-1 & 6.8 & Transcription factor & 56 \\
\hline MMP-2 & 6.3 & Protease & 57 \\
\hline$\beta_{2}$-Microglobulin ${ }^{\star}$ & 5.7 & Binds MHC class I & 58,59 \\
\hline Interleukin $11^{*}$ & 5.1 & Cytokine & 60 \\
\hline Cathepsin Z & 4.1 & Protease & 51 \\
\hline KC/Gro1* & 3.1 & Chemokine & 61 \\
\hline
\end{tabular}

Data are based on the expression profiling analysis described in ref. 18. AGenes previously described to contain functional NF- $\mathrm{kB}$-binding sites in their promoter/enhancer regions are indicated with an asterisk ( $\left.{ }^{\star}\right)$; genes lacking asterisks have also been described as genes regulated by $\mathrm{NF}-\kappa \mathrm{B}$, but either they are indirectly regulated or further experiments are required to demonstrate direct regulation. ${ }^{B}$ Fold change indicates fold upregulation of gene expression in EpRasXT versus EpRas cells (see Table 2 in ref. 18). ${ }^{C}$ References cite the first publication reporting regulation of gene in question by NF-кB. 


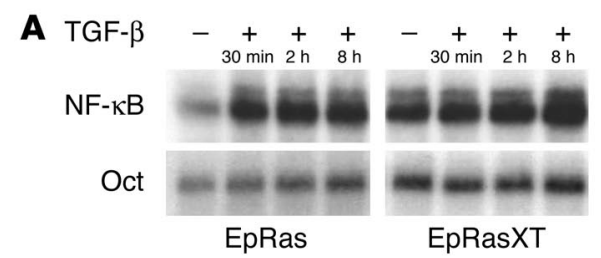

B

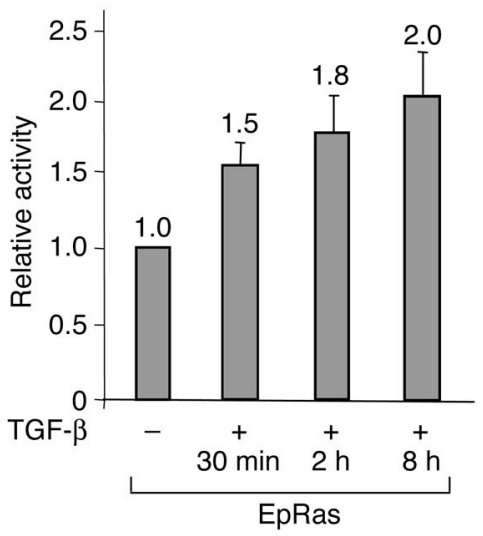

\section{Figure 2}

TGF- $\beta$ induces NF- $\kappa B$ activity in EpRas cells. (A) EpRas and EpRasXT cells were stimulated with TGF- $\beta 1(5 \mathrm{ng} / \mathrm{ml})$ for the indicated times. EMSA with whole-cell extracts $(6 \mu \mathrm{g})$ was performed with an NF-кBspecific probe (upper panel) and with an octamer-specific probe (lower panel) used as a control. (B) NF-KB transcriptional activity. EpRas cells were transiently transfected in triplicate with a $3 \times \kappa \mathrm{B}$.luc or $\beta$-globinTATA reporter construct. At 20 hours after transfection, cells were treated with TGF- $\beta 1(5 \mathrm{ng} / \mathrm{ml})$ for the indicated times. Then, the luciferase activities of extracts were determined and were normalized based on Renilla luciferase expression. The ratio of $3 \times \kappa$ B.luc and $\beta$-globin-TATA is shown. The expression level of unstimulated empty vector-infected EpRas cells was used as the reference luciferase activity and was arbitrarily set to 1 . Means and standard deviations are representative of two independent experiments carried out in triplicate. Bars represent standard deviations.

\section{Results}

Upregulation of NF-кB signaling during EMT. EpRas cells represent oncogenic, fully polarized, Ha-Ras-transformed EpH4 mammary epithelial cells that undergo EMT in response to TGF- $\beta$ both in tumors as well as in collagen gels, giving rise to mesenchyme-like cells (EpRasXT cells) in both cases. EpRasXT cells are characterized by a spindle-like morphology and gain of mesenchymal marker proteins, a phenotype stabilized by an autocrine TGF- $\beta$ loop in vitro and in vivo (refs. 19, 20; see Figure 1A). We wanted to determine whether NF-кB might play a role in the EMT process. We therefore analyzed whole-cell extracts from exponentially growing EpRas and EpRasXT cells by electrophoretic mobility-shift assay (EMSA). We detected some NF-кB DNAbinding activity in EpRas cells even without stimulation by known inducers of NF- $\mathrm{\kappa B}$ and consistently observed a 3- to 4-fold increase in NF-кB DNA-binding activity in EpRasXT cells (Figure 1B).

Based on those observations, we next asked whether NF-кB target genes were induced in mesenchymal EpRasXT cells to the same degree as their epithelial counterpart, EpRas cells. To address this question, we reanalyzed the data from a previously reported expression profile, in which we had performed microarray analysis of polysome-bound mRNAs to identify genes differentially expressed in EpRasXT compared with EpRas cells (Tables 2 and 3 in ref. 18). Interestingly, 13 of the 75 annotated genes upregulated during EMT had previously been described as NF-кB target genes (Table 1). In mesenchymal EpRasXT cells, several genes encoding NF-кB-regulated cytokines/chemokines (IL-11, JE/MCP-1, and $K C / G r o 1)$, proteases (MMP-13, cathepsin B, MMP-2, and cathepsin Z), hormones (cholecystokinin and placental proliferin 2), and the transcription factor Stat-1, as well as $\beta_{2}$-microglobulin were expressed at elevated levels compared with their epithelial counterparts. Furthermore, NF- $\mathrm{KB}$ has previously been shown to directly regulate the two EMT marker genes vimentin and tenascin $C$ (Table 1). In addition, $b c l-3$, a regulator of NF- $\kappa \mathrm{B}$ activity (24) and previously identified as being expressed in human breast cancer (25), is likewise induced in EpRasXT cells (18). In contrast, among the genes downregulated in EpRasXT cells, only one gene (thrombospondin 1) has been suggested to be regulated by NF-кB (ref. 26; reviewed in ref. 27). Thus, expression profiling results clearly indicate an enriched expression of NF- $\mathrm{B}$ target genes in mesenchymal EpRasXT cells, consistent with increased activity of NF-кB.

TGF- $\beta$ induces NF- $\mathrm{K} B$ activity during EMT. Based on the observation that TGF- $\beta$ signaling is essential for the induction of EMT in EpRas cells $(19,20)$, as well as reports that TGF- $\beta$ can modulate NF-кB activity in certain epithelial cells (28), we sought to test whether TGF- $\beta$ can affect NF- $\mathrm{KB}$ activity in EpRas and EpRasXT cells. In order to characterize changes in NF-KB DNA-binding activity after stimulation with TGF- $\beta 1$, we incubated cultures of EpRas and EpRasXT cells in the presence of TGF- $\beta 1$ and monitored the levels of NF-кB DNAbinding activity by EMSA. In EpRas cells, we observed a 3- to 4-fold induction of NF-KB DNA-binding activity within 30 minutes, while we observed no response to TGF- $\beta$ in EpRasXT cells (Figure 2A). The result with the EpRasXT cells was not surprising, given that the cells themselves produce TGF- $\beta$. In addition, EpRas and EpRasXT cells were transiently transfected with an NF- $\mathrm{BB}$-dependent luciferase reporter (3xkB.luc). Stimulation of EpRas cells with TGF- $\beta 1$ result$\mathrm{ed}$ in an increase of roughly 2 -fold in NF- $\mathrm{KB}$ transactivation activity within 2-8 hours (Figure 2B), whereas no increase was noted in EpRasXT cells (data not shown). Thus, TGF- $\beta$ stimulation leads to an induction of functionally active NF-кB in EpRas cells, while it

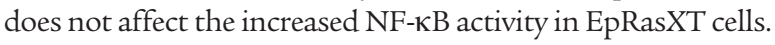

$N F-\kappa B$ is essential for EMT. To study the contribution of the IKK/ $\mathrm{I} \kappa \mathrm{B} \alpha / \mathrm{NF}-\kappa \mathrm{B}$ signaling module in the regulation of EMT and metastasis, we used retroviral gene transfer to express dominant interfering mutants of this pathway in EpRas cells. Infections were performed using retroviruses expressing a trans-dominant

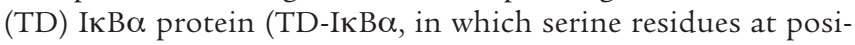
tions 32 and 36 are mutated to alanine residues, resulting in a nondegradable repressor), a constitutively active (CA) IKK-2 protein (CA-IKK-2, in which two serine residues in the activation loop are mutated to phosphomimetic glutamic acid residues), or an empty vector control. Stably infected cells were visualized by immunofluorescence microscopy, as the retroviruses coexpress enhanced GFP. Expression of TD-IкB $\alpha$ and CA-IKK-2 in cells from the $\phi N X$ producer line and in stably infected EpRas cells was 
A

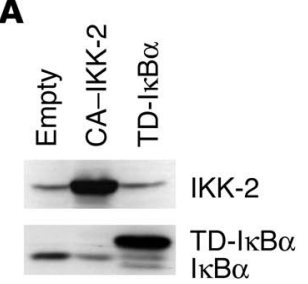

B

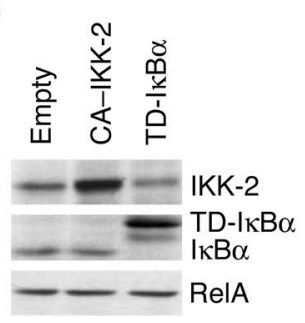

C Empty $\underline{\text { CA-IKK-2 TD-IKB } \alpha}$

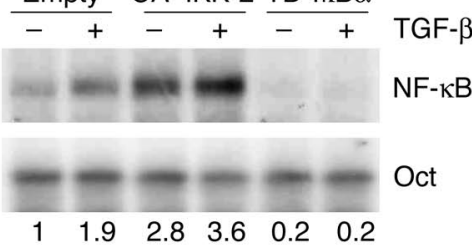

D

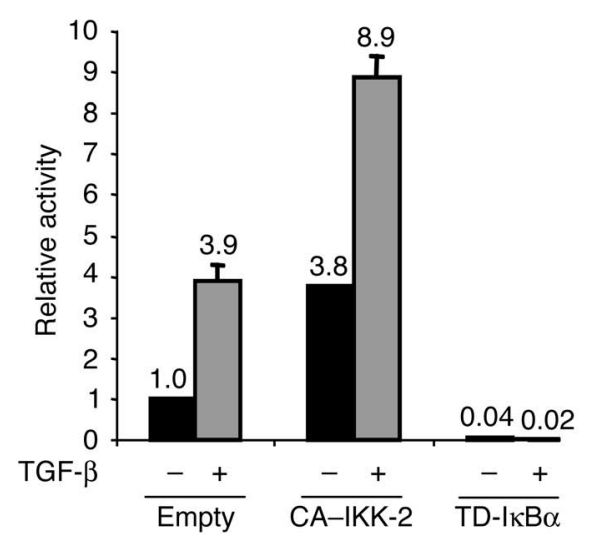

E

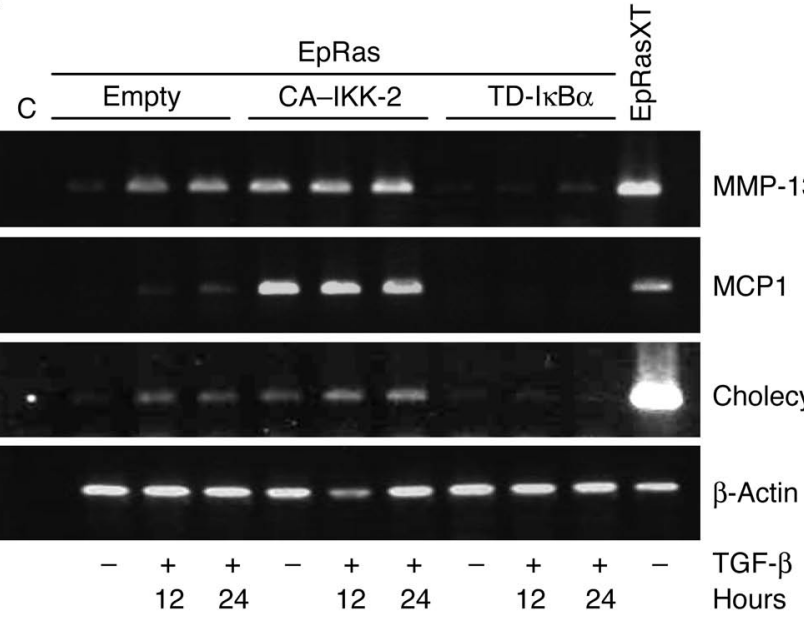

Figure 3

Modulation of NF-KB activity in EpRas cells. (A and B) Expression levels of dominant interfering mutants in $\Phi$ NX producer cells (A) and in stably infected EpRas cells (B) were determined by Western blot analysis of whole-cell extracts, using IKB $\alpha$ - and IKK-specific antibodies CA-IKK-2, endogenous IKK-2 (comigrating with CA-IKK-2), TD-IKB $\alpha$, and endogenous IKB $\alpha$. Equal loading was assessed using a p65/RelA-specific antibody (B, bottom panel). (C) Extracts from stably infected EpRas mutants left untreated (-) or stimulated with TGF- $\beta$ (5 ng/ml) for 2 hours (+) were analyzed by EMSA with an NF-kB-specific probe (upper panel) and with an octamer-specific probe (lower panel) as loading control. Quantified relative DNA-binding levels are indicated. (D) Stably infected cells were transiently transfected in triplicate with $3 \times \kappa$ B.luc or $\beta$-globinTATA reporter constructs. After 24 hours, cells were treated with TGF- $\beta$ ( $5 \mathrm{ng} / \mathrm{ml}$ for 4 hours) (+) or were left untreated (-). Luciferase activity was measured and normalized based on Renilla luciferase expression (as described in Figure 2B). The ratio of 3xкB.luc and $\beta$-globin-TATA is shown. Expression levels of unstimulated empty vector-transfected EpRas cells were used as a reference and arbitrarily set to 1 . Bars represent standard deviations. (E) EpRas mutants and EpRasXT cells were stimulated with TGF- $\beta(5 \mathrm{ng} / \mathrm{ml})$ for the times indicated, and RT-PCR analysis was carried out for transcript expression of MMP-13, MCP-1, cholecystokinin, and $\beta$-actin, as described in Methods. C, control (water); Empty, EpRas cells infected with empty vector control.

assessed by Western blot (Figure 3, A and B). This analysis revealed strong overexpression of the mutant proteins compared with that of the endogenous counterparts. As previously observed in another cellular system (29), the presence of high levels of exogenous $\mathrm{TD}-\mathrm{I} \kappa \mathrm{B} \alpha$ resulted in reduced expression of endogenous I $\mathrm{B} \alpha \alpha$, most

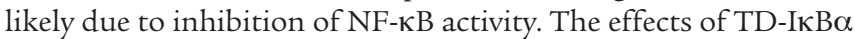
and CA-IKK-2 expression in EpRas cells on NF-кB DNA-binding activity were analyzed by EMSA. In EpRas cells infected with TD-

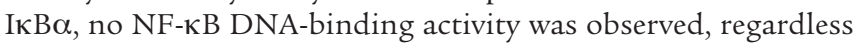
of whether cells were left unstimulated or were stimulated with TGF- $\beta$ (Figure 3 C), TNF- $\alpha$, or PMA (data not shown). In contrast, cells infected with CA-IKK-2 exhibited 2- to 3-fold increased DNA-binding activity in the unstimulated state (compared with unstimulated EpRas control cells), and showed a roughly 2-fold higher induction of NF- $\mathrm{\kappa B}$ activity after being stimulated with TGF- $\beta$, compared with TGF- $\beta$-treated EpRas control cells. Transient transfection of these cells with $3 \times 1$ B.luc and subsequent luciferase assays revealed a 3- to 4-fold induction of luciferase activity in untreated EpRas cells infected with CA-IKK-2 and a more than 2 -fold higher induction upon treatment with TGF- $\beta$, compared with that of unstimulated or TGF- $\beta$-treated EpRas control cells, respectively. In contrast, NF- $\kappa \mathrm{B}$ transcriptional activity was virtually completely inhibited before and after treatment with TGF- $\beta$ in EpRas cells expressing TD-IкB $\alpha$ (Figure 3D). In addition, RT-PCR analysis of a subset of NF- $\mathrm{BB}$-regulated target genes that are associated with EMT (Table 1) (18) was performed with the EpRas mutants before and after TGF- $\beta$-induced EMT. This analysis showed induction of MMP-13, MCP-1, and cholecystokinin in CA-IKK-2-expressing EpRas cells in the absence of TGF- $\beta$ (in the case of $M C P-1$, this was even comparable to the expression level in EpRasXT cells), and slightly stronger expression of these genes in the presence of TGF- $\beta$ (cholecystokinin and MMP-13), whereas expression and TGF- $\beta$-induced upregulation of these genes were almost completely blocked in TD-IKB $\alpha$-expressing cells (Figure $3 \mathrm{E}$ ). Based on these results, NF- $\mathrm{\kappa B}$ activates at least a subset of genes in the TGF- $\beta$-induced genetic program underlying EMT.

We then asked whether this modulation in NF-кB activity affected the ability of EpRas cells to undergo EMT. On porous support (filters) allowing epithelial polarization, EpRas cells infected with empty vector (like uninfected cells) showed a fully polarized epithelial phenotype with basolateral plasma membrane expression of the epithelial marker E-cadherin, but no expression of the mesenchymal marker vimentin (Figure 4, A-D). Treatment of these EpRas cells with TGF- $\beta$ for 5 days resulted in strands of spindle- 
A

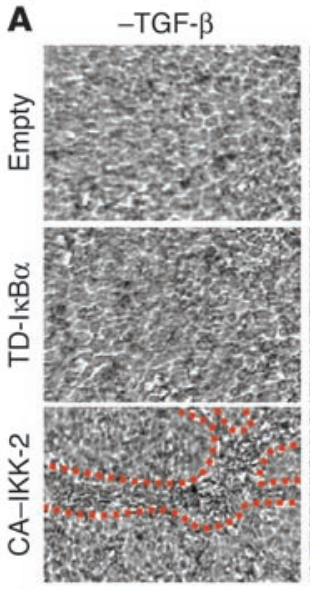

D
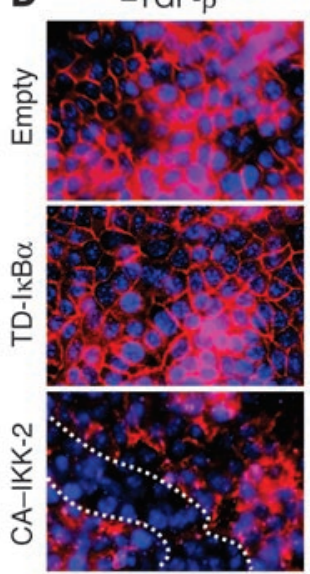

E-cadherin/DNA
+TGF- $\beta$

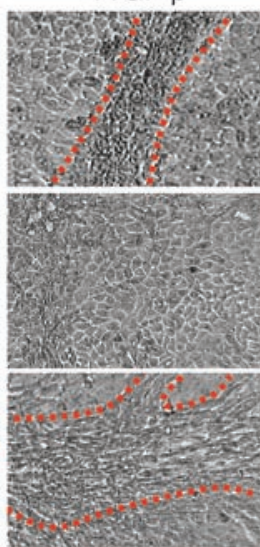

+ TGF- $\beta$
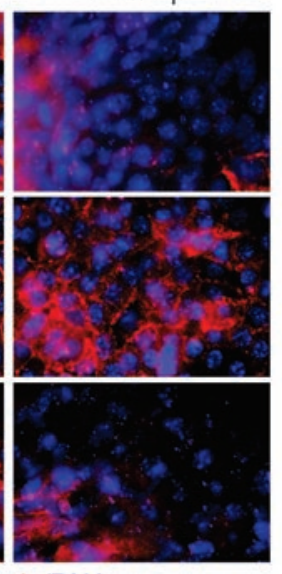

B
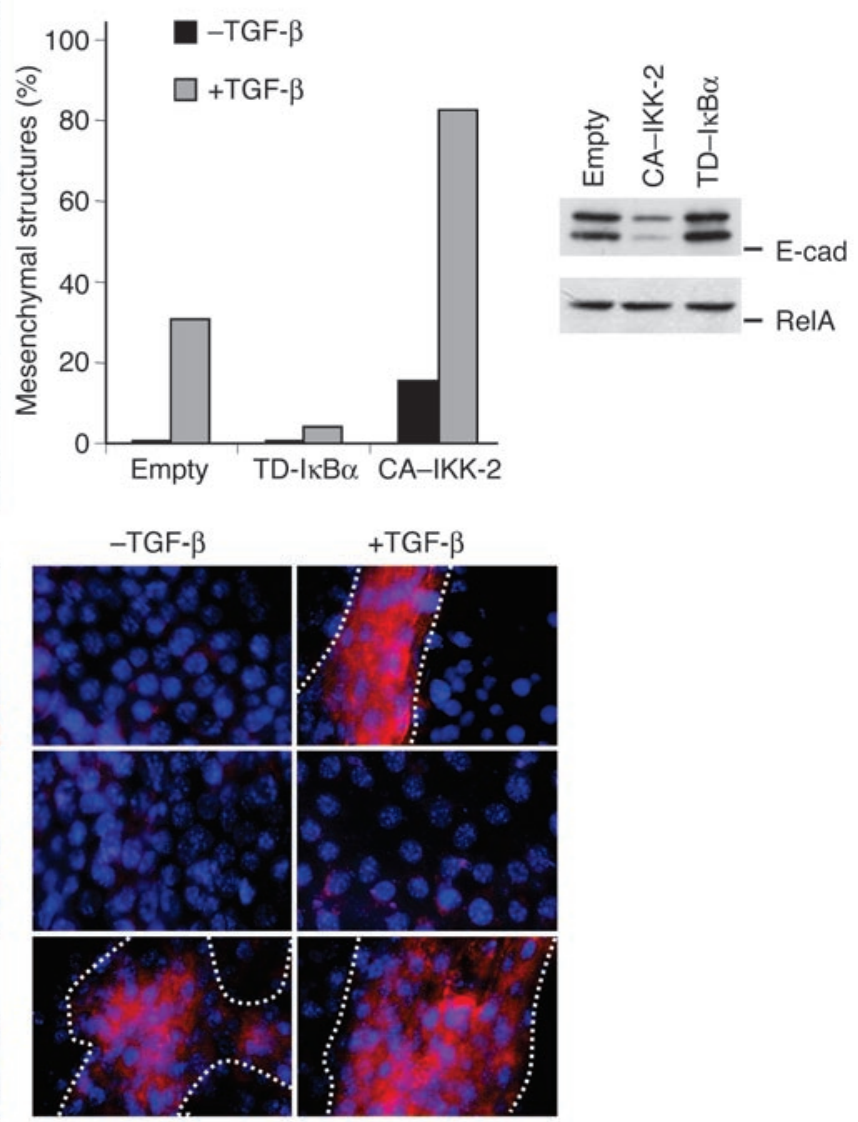

Vimentin/DNA

Figure 4

EpRas cells expressing TD-IKB $\alpha$ fail to undergo EMT, while CA-IKK-2 expression drives EMT in the absence of TGF- $\beta$ (analysis on porous support). EpRas cells expressing the empty vector control, TD-IKB $\alpha$, or CA-IKK-2 were cultivated on porous supports for 7 days in the presence (+) or absence (-) of TGF- $\beta$ (5 ng/ml; days 2-7). (A) Photographs of cultivated cells are shown; regions with strands of spindle-shaped mesenchymal cells are indicated by red dotted lines. Original magnification, $\times 100$. (B) Quantification of the area on porous supports covered by mesenchymal strands as percentage relative to total area covered by adherent cells (cultures shown in $\mathbf{A}$; day 6 ). (C) E-cadherin levels in EpRas cells expressing empty vector, TD-IKB $\alpha$, or CA-IKK-2 and not treated with TGF- $\beta$ were determined by Western blot analysis with an E-cadherin-specific antibody (E-Cad; upper panel). Subsequent stripping and reprobing of the blot with a p65/RelA-specific antibody (lower panel) was done to demonstrate equal loading. (D) Cells as indicated were cultivated on porous supports for 7 days in the presence or absence of TGF- $\beta$ ( $5 \mathrm{ng} / \mathrm{ml}$; days 2-7). Cells were immunostained for E-cadherin or vimentin (red) with DAPI counterstaining for DNA (blue), as described in Methods. Regions of mesenchymal, E-cadherin-negative and vimentin-positive cells are outlined by white dotted lines and correspond to the "mesenchymal" areas shown in A (red dotted lines). Original magnification, $\times 400$.

shaped, vimentin-positive cells only weakly expressing E-cadherin (Figure 4, A, B, and D). No phenotypic changes or changes in marker expression compared with EpRas control cells were observed in TD-IKB $\alpha$-expressing cells in the absence of TGF- $\beta$ (Figure $4, \mathrm{~A}-\mathrm{D}$ ). Upon treatment with TGF- $\beta$, however, a considerable proportion

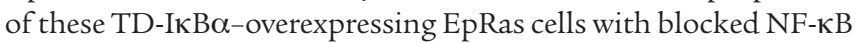
activity rapidly detached from porous supports as a consequence of cell death. The remaining cells almost completely failed to undergo EMT (Figure 4A). TGF- $\beta$-treated TD-IкB $\alpha$-expressing EpRas cells lacked the strands of spindle-shaped mesenchymal cells that were abundant in empty virus-infected EpRas control cultures (Figure 4, A and B). The same cells failed to upregulate vimentin and retained high levels of E-cadherin, which was partially redistributed to the cytoplasm, indicating some loss of polarity (Figure 4D). Surprisingly, CA-IKK-2-overexpressing EpRas cells with increased NF-кB activity were able to undergo EMT at a considerable rate even in the absence of TGF- $\beta$ (Figure 4 , A and B). After cells had grown for 6 days on porous support, we observed strands of spindle-shaped, E-cadherin-negative and vimentinpositive cells that covered more than $10 \%$ of the total surface area (Figure 4, A, B, and D). When we analyzed bulk cultures of these cells by Western immunoblot, we observed a strong reduction in E-cadherin levels (Figure 4C). Consistent with these observations, we noted enhanced EMT in CA-IKK-2-expressing cells upon TGF- $\beta$ treatment compared with that of control EpRas cells, as indicated by a higher percentage of spindle-shaped cells with cytoplasmic (depolarized) or no E-cadherin expression, and strong vimentin expression (Figure 4, A, B, and D). Importantly, very similar results were obtained when the CA-IKK-2 and TD-IкB $\alpha$ transgenes were introduced into V12S35Ras cells. These cells represent another 

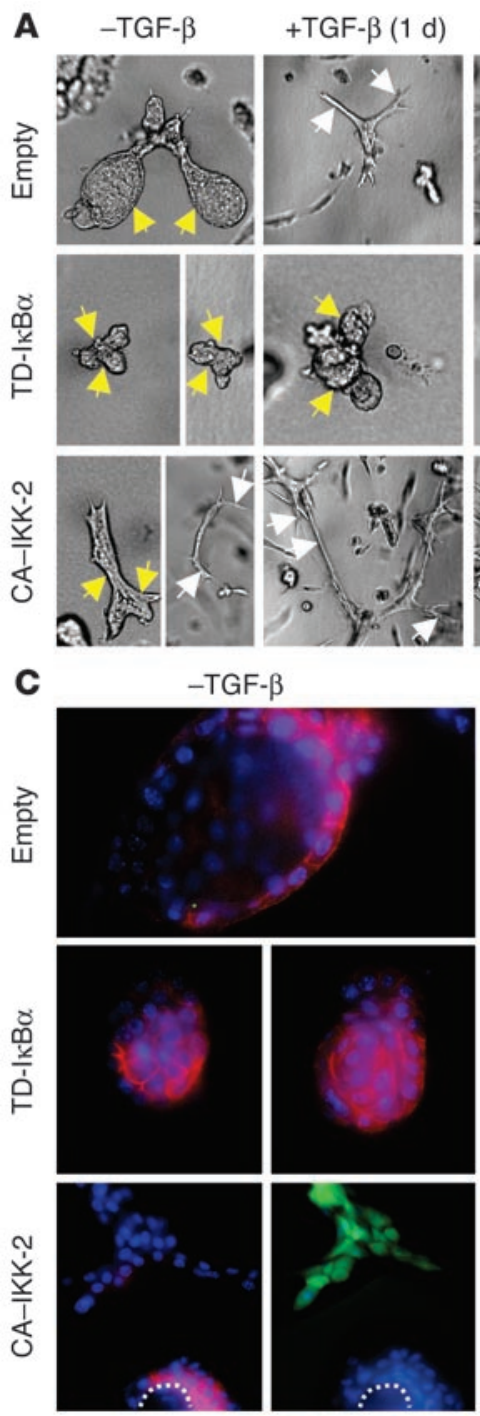

E-cadherin/DNA/GFP

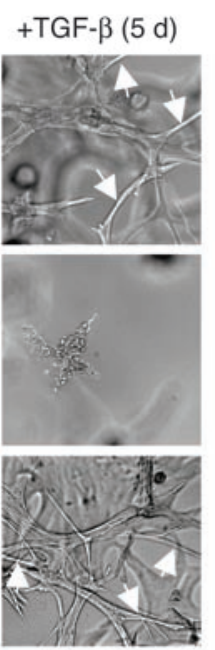

+ TGF- $\beta$
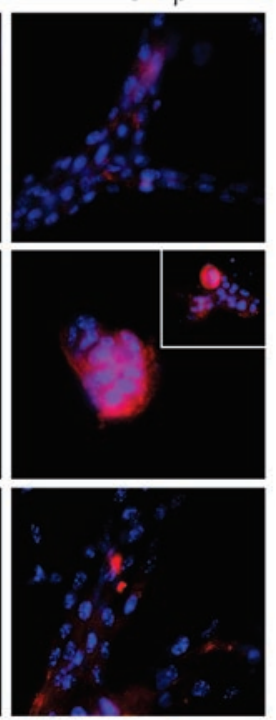
P
B
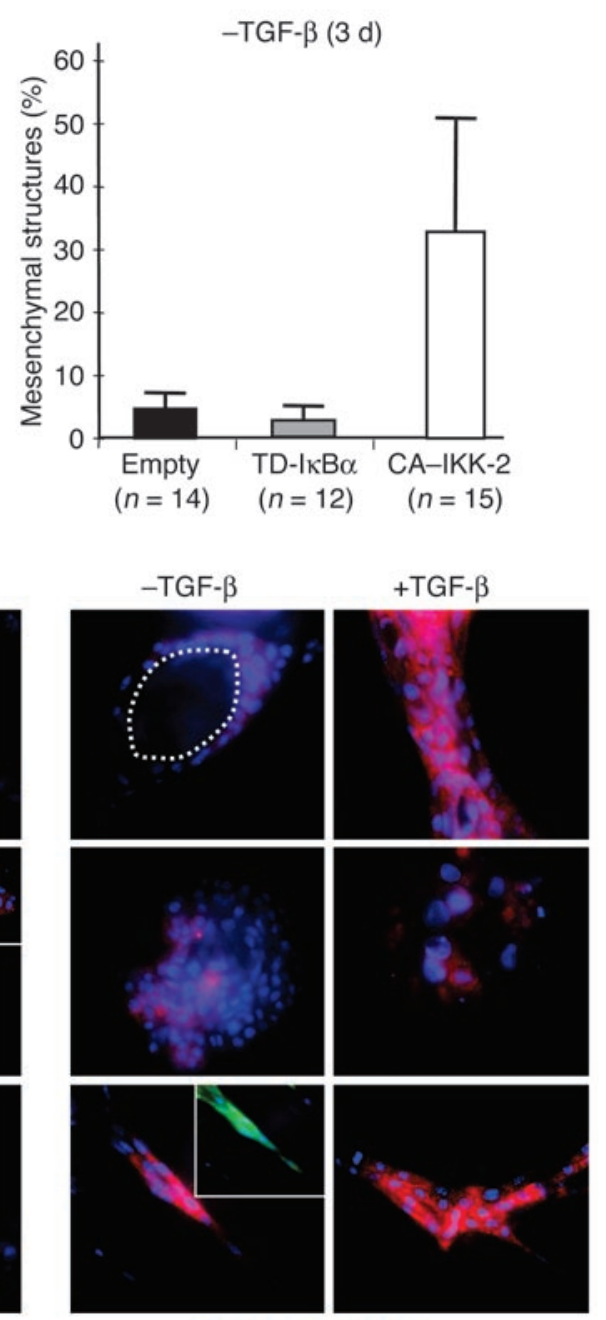

Vimentin/DNA/GFP

\section{Figure 5}

TD-IKB $\alpha$ expressed in EpRas cells prevents EMT, whereas CA-IKK-2 induces EMT in the absence of TGF- $\beta$ (analysis in collagen gels). EpRas cells expressing the empty vector control, TD-IKB $\alpha$, or CA-IKK-2 were seeded into collagen gels, were allowed to form structures for 3-5 days, and were left untreated for no induction (-) or were induced to undergo EMT by the addition of TGF- $\beta$ (+) for 5-6 days. (A) Left column, culture without TGF- $\beta$ for 7 days; middle column, culture without TGF- $\beta$ for 5 days, plus TGF- $\beta$ treatment ( $5 \mathrm{ng} / \mathrm{ml}$ ) for 1 day; right column, culture without TGF- $\beta$ for 5 days, plus TGF- $\beta$ treatment $(5 \mathrm{ng} / \mathrm{ml}$ ) for 5 days. Photographs of representative tubular structures with lumina (yellow arrows) or distended chords and strands of invasive cells with mesenchymal morphology (white arrows) are shown. Original magnification, $\times 100$. (B) Quantification of mesenchymal structures (see white arrows in A for the CA-IKK-2, -TGF- $\beta$ culture) as the percentage relative to that of 60 randomly chosen structures per gel after 3 days of culture in the absence of TGF- $\beta$. Below graph, $n$ indicates the number of collagen gels analyzed. Bars represent the standard deviations obtained in analyzing individual collagen gels. (C) Collagen gel structures were stained for the epithelial marker E-cadherin (first and second columns) or the mesenchymal marker vimentin (third and fourth columns). Bottom row, second from left (CA-IKK-2-expressing cells, -TGF- $\beta$ ): GFP expression (green) of structures stained for E-cadherin. Inset, third panel from left, middle row (TD-IKB $\alpha$-expressing cells, + TGF- $\beta$ ): disintegrating structure stained for E-cadherin. Inset, second panel from right, bottom row (CA-IKK-2-expressing cells, -TGF- $\beta$ ): GFP expression (green) of structures stained for vimentin. Original magnification, $\times 400$.

monogenic transformed cell line, independently generated from the original EpH4 cells and transformed by an effector mutant of a different oncogenic Ras that induces hyperactive ERK/MAPK but not PI3K signaling (17). We observed an inhibition of EMT in TD-IKB $\alpha$-expressing cells and a considerable rate of spontaneous EMT in the absence of TGF- $\beta$ in CA-IKK-2-expressing V12S35Ras cells that occurred even more frequently than in CA-IKK-2-express- ing EpRas cells (see Supplemental Figure 1; supplemental material available at http://www.jci.org/cgi/content/full/114/4/569/DC1). Thus, the role of NF-кB in the regulation of EMT is not limited to a single cell line.

A more physiological culture system to analyze epithelial cell behavior and plasticity are three-dimensional serum-free collagen I gel cultures (15). In these cultures, fully polarized EpRas control 
A

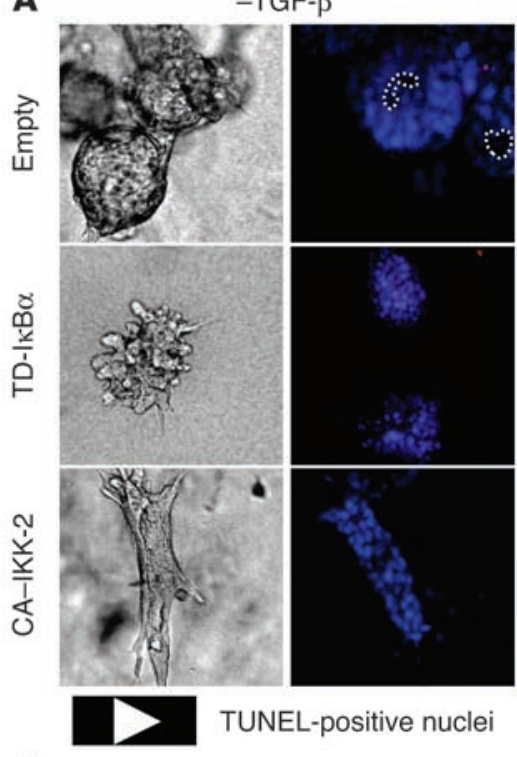

C

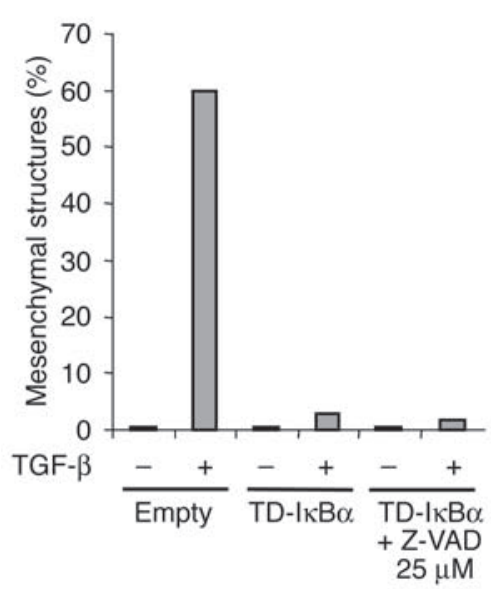

+TGF- $\beta$

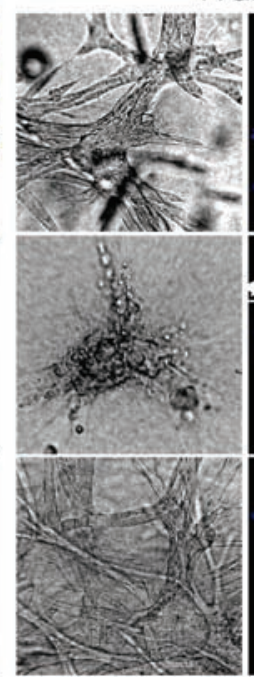

\section{$\beta$}

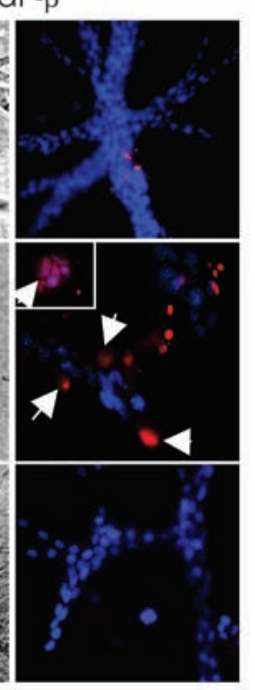

D

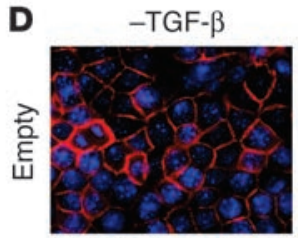

-TGF- $\beta$
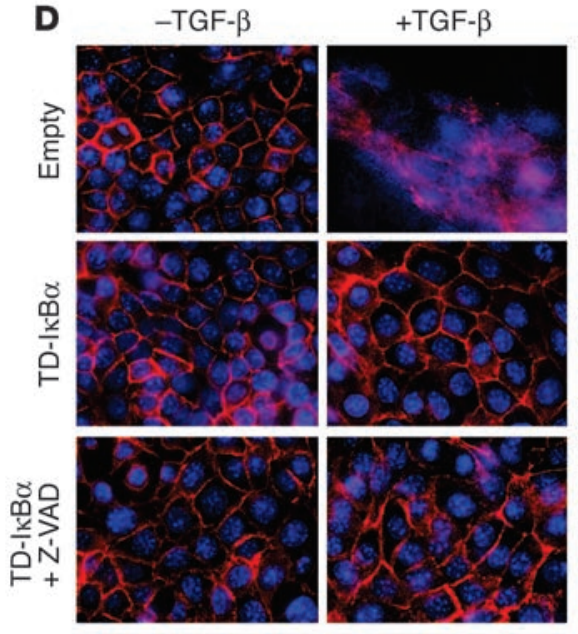

E-cadherin/DNA
B

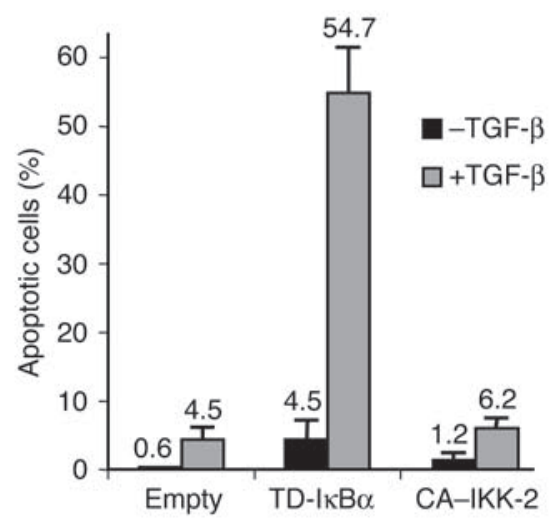

\section{Figure 6}

Suppression of NF-kB activity in EpRas cells leads to apoptosis and prevents EMT. (A) EpRas cells expressing the empty vector control, TD-IKB $\alpha$, or CA-IKK-2 were seeded into collagen gels, were allowed to form structures for 3 days, and were treated with TGF- $\beta$ for 6 days or were left untreated. Collagen cultures were subjected to in situ TUNEL staining (red) and DAPI staining (blue, indicating living cells). Light microscopy images of collagen gels from the same experiment photographed prior to TUNEL staining are also shown. Arrows indicate TUNEL-positive nuclei. Inset, right middle panel: another structure with TUNEL-positive nuclei. Original magnification, $\times 200$. (B) Quantification of TUNEL-positive cells from collagen gel structures shown in A. TUNEL staining of nuclei was assessed in at least 300 cells from three to six randomly chosen fields. The average from two to three collagen gels was used to calculate the apoptotic index and standard deviation. Average percentage of apoptotic cells, assessed in 2-3 collagen gels (at least 300 cells per gel) for each cell type, are indicated above bars. (C) EpRas cells expressing the empty vector control or TD-IKB $\alpha$ were cultivated for 5 days on porous support in the presence or absence of $25 \mu \mathrm{M} Z$ Z-VAD-FMK (Z-VAD; days 0-5) and/or TGF- $\beta(5 \mathrm{ng} / \mathrm{ml}$; days $1-5)$. The quantification of the area on porous support covered by mesenchymal strands is shown as the percentage relative to the total area covered by adherent cells (at day 4, after 3 days with or without TGF- $\beta$ treatment). (D) Cells as indicated (with or without $25 \mu \mathrm{M}$ Z-VAD-FMK; days $0-5)$ were cultivated on porous support for 5 days in the presence or absence of TGF- $\beta$ ( $5 \mathrm{ng} / \mathrm{ml}$; days $1-5)$. Cells were immunostained for E-cadherin or vimentin (red) plus DAPI counterstaining for DNA (blue) after 5 days of culture on porous support. Original magnification, $\times 400$.

cells form tubular and alveolar structures with large lumina (Figure 5A). These cells show basolateral membrane (polarized) expression of E-cadherin, but no vimentin expression (Figure 5C). Upon addition of TGF- $\beta 1$, EpRas control cells underwent EMT, as shown by a spindle-shaped and migratory phenotype, loss of E-cadherin, and de novo expression of vimentin after 6 days of treatment (Fig- ure 5, A and C). Untreated TD-IкB $\alpha$ cells resembled control EpRas cells in that they formed epithelial structures (tubular structures with lumina) and showed basolateral E-cadherin staining and no vimentin expression. Despite this resemblance, TD-IкB $\alpha$ epithelial structures appeared more compact and smaller in size (Figure 5, A and C). Upon treatment with TGF- $\beta$, epithelial structures formed 

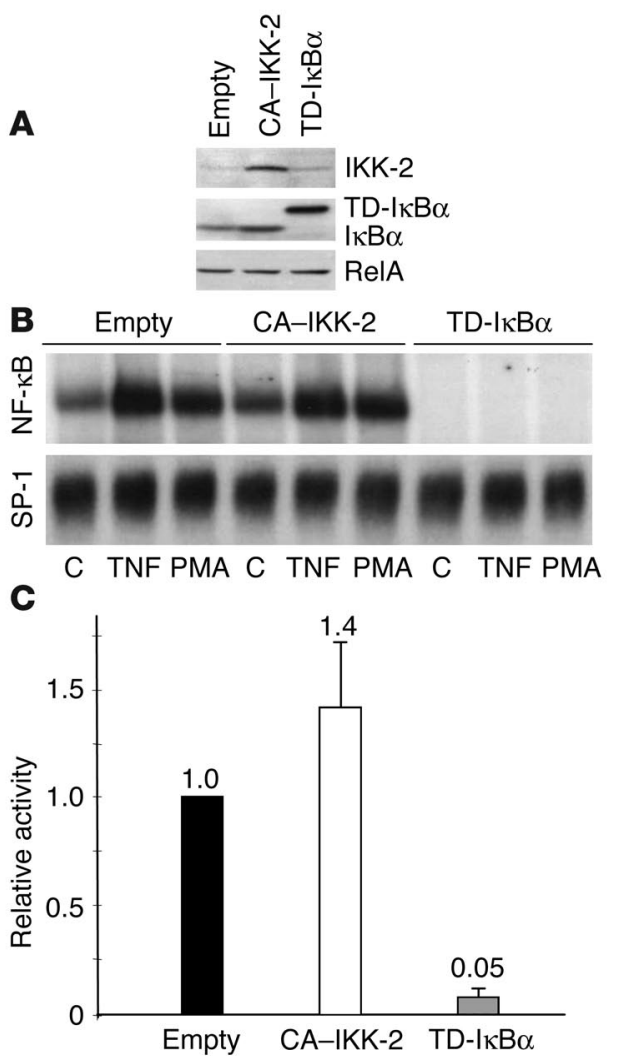

by TD-IкB $\alpha$-expressing EpRas cells retained E-cadherin expression (Figure 5C), but rapidly disintegrated (Figure 5, A and C). Only a very small fraction of the structures (about $0.5 \%$ ) formed unordered cell strands before disintegration (data not shown). In contrast, untreated CA-IKK-2-expressing cells with increased NF- $\mathrm{B}$ activity formed two types of structures. While a large proportion of epithelial tubular structures with lumina were apparent (Figure $5 \mathrm{~A}$ ), a significant number of the structures consisted of unordered cell strands with spindle-like cellular morphology, resembling control EpRas cells treated with TGF- $\beta$ (Figure 5, A and B). Interestingly, among the epithelial structures resembling control EpRas cells (E-cadherin positive and vimentin negative), a large percentage had either lost or downregulated expression of CA-IKK-2, as indicated by low levels of the coregulated GFP expression (Figure $5 \mathrm{C}$, bottom). In contrast, mesenchymal structures generated by untreated CA-IKK-2-expressing cells were E-cadherin negative, expressed vimentin, and showed strong GFP staining, indicative of high transgene expression (Figure 5C). Thus, high levels of CA-IKK-2 expression appear to promote EMT even in the absence of TGF- $\beta$. As expected, TGF- $\beta$ treatment induced the remaining epithelial CA-IKK-2-expressing EpRas cells to rapidly form mesenchymal structures expressing vimentin but no E-cadherin (Figure 5, A and C). We also determined whether a strong NF-кB activator such as TNF- $\alpha$ would induce EMT. Indeed, we observed a small number of mesenchymal structures expressing vimentin in TNF- $\alpha$-treated EpRas collagen gel cultures, even in the absence of TGF- $\beta$ (Supplemental Figure 2). In conclusion, an activated NF- $\kappa \mathrm{B}$ pathway plus Ras is sufficient to cause EMT, whereas inhibition of NF- $\kappa \mathrm{B}$ activity prevents EMT, causing disintegration of structures formed in collagen.

\section{Figure 7}

Effect of retrovirus-expressed TD-IKB $\alpha$ and CA-IKK-2 on NF-кB activity in EpRasXT cells. (A) Expression levels of dominant interfering mutants compared with that of their endogenously expressed wildtype counterparts in stably infected EpRasXT cells were determined by Western blot analysis of whole-cell extracts using $I_{\kappa} B \alpha-$ and IKKspecific antibodies for visualization. Protein bands of CA-IKK-2/endogenous IKK-2 (comigrating), TD-I $\mathrm{B} \alpha$, and endogenous $\mathrm{I} \kappa \mathrm{B} \alpha$ are indicated. Equal loading was assessed by stripping and reprobing of blots with a p65/RelA antibody (bottom panel). (B) Stably infected EpRasXT cells were not treated (control) or were stimulated with TNF- $\alpha$ (TNF; 40 $\mathrm{ng} / \mathrm{ml}$ ) for 1 hour or with PMA (50 ng/ml) for 1 hour. Then, NF-kB DNAbinding activity was assessed with an NF-kB-specific probe (upper panel) or with an Sp-1-specific probe (lower panel) as a loading control. (C) NF-kB transcriptional activity in the EpRasXT derivatives described in $\mathbf{A}$ and $\mathbf{B}$ was determined by luciferase assay, as described in Figure 3D. The expression level of empty vector-transfected EpRasXT cells was used as a reference luciferase activity and was arbitrarily set to 1 . Mean values are indicated above bars.

$N F-\kappa B$ is required both for protection from $T G F-\beta$-induced apoptosis and for direct promotion of EMT. The previous experiments showed that NF- $\kappa \mathrm{B}$ can, at least in part, substitute for TGF- $\beta$ in the induction of EMT in collaboration with Ras. We next addressed the mechanistic consequence of NF-кB inhibition with respect to the prevention of EMT. Because we observed rapid disintegration of TD-IкB $\alpha-$ expressing structures upon TGF- $\beta$ treatment, we assessed their apoptotic response under these conditions. EpRas control cells as well as TD-IKB $\alpha$ - and CA-IKK-2-expressing derivatives were allowed to form organotypic structures in collagen gels for 3 days. Then they were induced to undergo EMT by TGF- $\beta$ or were left untreated. TGF- $\beta$-treated TD-I $\mathrm{B} \alpha$-expressing EpRas structures showed cell disintegration due to apoptosis, as determined by in situ TUNEL staining (Figure 6A). As shown in Figure 6B, approximately $55 \%$ of these cells were TUNEL positive and were thus apoptotic after 6 days of TGF- $\beta$ treatment. Moreover, TD-IкB $\alpha$ cells showed a slight elevation in induction of apoptosis compared with control EpRas cells even in the absence of TGF- $\beta$ ( $4.5 \%$ versus $0.6 \%$ ), possibly explaining the smaller size of epithelial structures formed by TD-I $\mathrm{B} \alpha$-expressing cells in collagen gels. Finally, EpRas cells expressing CA-IKK-2 showed low levels of apoptosis, comparable to that of EpRas control cells. We then asked whether the observed failure of TD-IкB $\alpha$-expressing EpRas cells to undergo EMT (Figures 4 and 5) was exclusively due to inhibition of the antiapoptotic

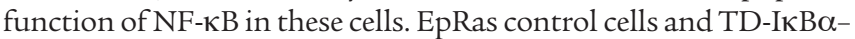
expressing derivatives were cultured on porous support. Treatment of TD-IкB $\alpha$-expressing EpRas cells with $25 \mu \mathrm{M}$ cell-permeable caspase inhibitor benzyloxycarbonyl-Val-Ala-Asp-fluoromethylketone (Z-VAD-FMK) strongly suppressed the TGF- $\beta$-induced apoptosis seen in these cells (on porous support as well as in collagen gels; Figure 6B), to a level that was comparable to that of EpRas control cells (data not shown). Importantly, neither mesenchymal structures (as seen in TGF- $\beta$-treated EpRas control cells) nor loss of polarized E-cadherin expression or de novo vimentin expression was observed in these Z-VAD-FMK-treated TD-IKB $\alpha$-expressing EpRas cells after 4 days of stimulation with TGF- $\beta$ (Figure 6, C and D). Notably, due to the significant fraction of apoptotic cells following TGF- $\beta$ treatment, small areas of irregular structures were detected in the TD-IкB $\alpha$-expressing EpRas cultures (data not shown). These were not observed when apoptosis was blocked by Z-VAD-FMK. In summary, NF- $\kappa \mathrm{B}$ signaling is required in Ras- 
A
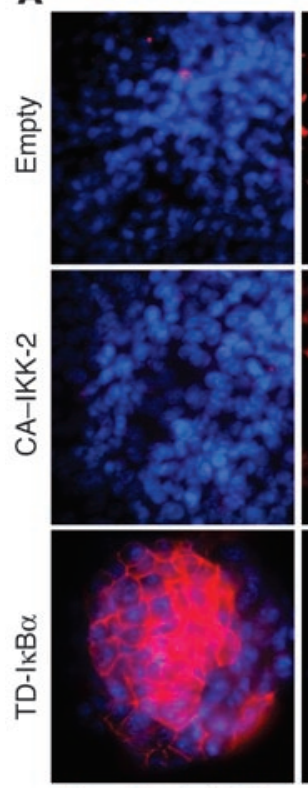

E-cadherin/DNA
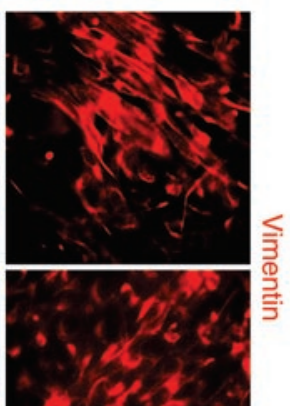

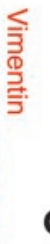

C

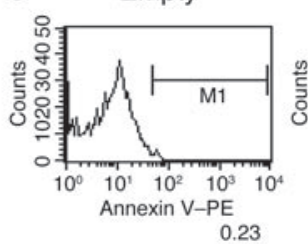

Empty

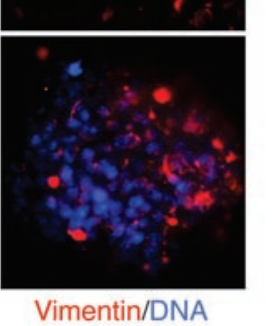

$\mathbf{B}$

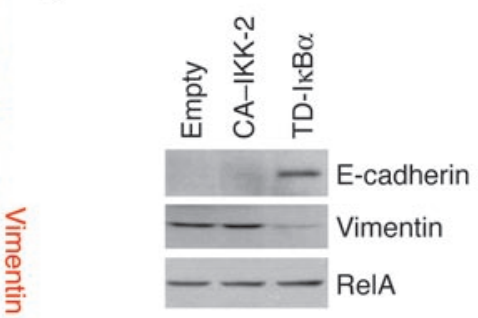

\section{Figure 8}

Inhibition of NF-kB activity in mesenchymal EpRasXT cells causes reversal of EMT. EpRasXT cells expressing the empty vector control, TD-IKB $\alpha$, or CA-IKK-2 were cultivated on porous supports for 6 days. (A) Cells were immunostained for E-cadherin (red; left column) or vimentin (red; right column) and were counterstained for DNA (blue; omitted in top and middle panels, right column). Original magnification, $\times 200$. (B) E-cadherin and vimentin levels were determined by Western blot analysis with antibodies specific for E-cadherin and vimentin, respectively. Subsequent stripping and reprobing of the blot with a p65/RelA-specific antibody was carried out to show equal loading (bottom panel). (C) EpRasXT cells infected with either the TD-IKB $\alpha$-expressing virus or the control virus were grown on porous supports to allow EMT reversal in TD-IKB $\alpha$ cells. Apoptotic cells were identified by annexin $\mathrm{V}$ staining and FACS analysis.

transformed cells for protection from TGF- $\beta$-induced apoptosis during EMT. Moreover, NF-אB plays an additional role as a direct regulator of the EMT program, as blockade of apoptosis does not restore the ability of TD-IKB $\alpha$-expressing EpRas cells to undergo EMT in response to TGF- $\beta$.

Inbibition of NF- $\mathrm{K} B$ activity in mesenchymal EpRasXT cells causes reversal of EMT. We next addressed whether interference with NF-кB activity would also affect the mesenchymal EpRasXT cells that have completed EMT. EpRasXT cells were again stably infected with retroviruses expressing TD-IKB $\alpha$ or CA-IKK-2 or with a GFP-only empty control vector. Transgene expression, as assessed by Western blot analysis, is shown in Figure 7A. EMSA showed complete inhibition of NF-KB DNA-binding activity in untreated and TNF- $\alpha$ - or PMA-stimulated EpRasXT cells expressing TD-IкB $\alpha$. The expression of CA-IKK-2 resulted only in a moderate (less than 2-fold) enhancement of NF- $\mathrm{KB}$ activity in untreated cells (Figure 7B). Transient transfection with $3 \times 6$ B.luc and subsequent luciferase assays revealed a strong blockade of NF- $\mathrm{KB}$ transactivation activity in EpRasXT cells expressing TD-IкB $\alpha$, while a moderate increase of luciferase activity was observed in EpRasXT cells infected with CA-IKK-2.

To test whether TD-IKB $\alpha$ was able to revert EMT, we cultured EpRasXT cells expressing TD-IкB $\alpha$, CA-IKK-2, or the control vector on porous support. As expected, CA-IKK-2- and control vectorexpressing EpRasXT cells showed a mesenchymal, spindle-shaped

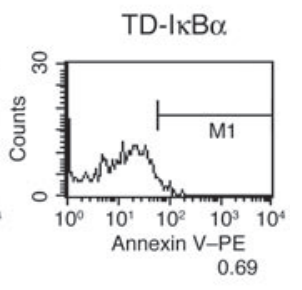

0.69 phenotype and expressed high levels of vimentin, but no E-cadherin (Figure 8, A and $\mathrm{B})$. Interestingly, however, a large percentage of TD-IкB $\alpha$-expressing cells reverted to an epithelial phenotype, in which the cells formed compact structures, regained marked E-cadherin expression at the plasma membrane, and almost completely lost expression of vimentin, as demonstrated by immunofluorescence (Figure 8A) and Western blot analysis (Figure 8B). Similar results were obtained under different culture conditions (data not shown). TDI $\mathrm{B} \alpha$-expressing EpRasXT cells showed no obvious signs of cell death when cultured on porous support (e.g., condensed nuclei, disintegrated cells, and detachment from porous support). Annexin $V$ staining (Figure 8C) as well as cell cycle analysis (data not shown) of TD-IкB $\alpha$-expressing EpRasXT cells that had reverted to an epithelial phenotype demonstrated that reverted epithelial cells were still viable and healthy. These results indicate that NF-кB activity is required for maintenance of the mesenchymal phenotype of Ras-transformed cells that have undergone EMT.

$N F-\kappa B$ is required for the metastatic potential of EpRas cells in vivo. EpRas cells undergo EMT in vivo in response to endogenous TGF- $\beta$ (19). TGF- $\beta$-induced EMT of EpRas cells is tightly linked to their ability to form lung metastases, evident after tail vein injection of cultured EpRas cells (S. Grünert and H. Beug, unpublished data) or cells recultivated from EpRas-induced primary mammary tumors (17). Because NF-KB activity was found to be essential for both the induction and maintenance of EMT, we sought to determine whether NF- $\mathrm{kB}$ signaling is also required for metastatic potential induced by Ras plus TGF- $\beta$ in vivo and whether inhibition of NF-kB would abrogate this metastatic ability. The metastatic potential of TD-IкB $\alpha$-expressing EpRas cells and EpRas control cells was assayed by injection of cultured cells into the tail vein of nude mice. Mice injected with EpRas control cells rapidly died from numerous large metastases (on average, 3-4 weeks after tail vein injection), while mice receiving TD-IKB $\alpha$-expressing EpRas cells appeared healthy at the time of death of the mice injected with EpRas control cells. Mice injected with EpRas cells with blocked NF- $\mathrm{KB}$ activity showed a 2 -fold decrease in lung weight (compared with that of control mice of similar age; data not shown) and had only a few small (micro-) metastases (average number, 16.6 metastases per lung) by histological analysis, compared with an average number of 171.0 metastases per lung in animals injected with EpRas control cells (Figure 9, A-C). To verify that TD-IкB $\alpha$-expressing EpRas cells were still able to form primary tumors in a fashion similar to that of EpRas control cells, we injected the cell types described above (in each case from the same batches as used for tail vein injections) into mammary gland fat pads of nude mice. After 3 weeks, both EpRas control cells as well as EpRas cells expressing TD-IкB $\alpha$ formed tumors, which differed 

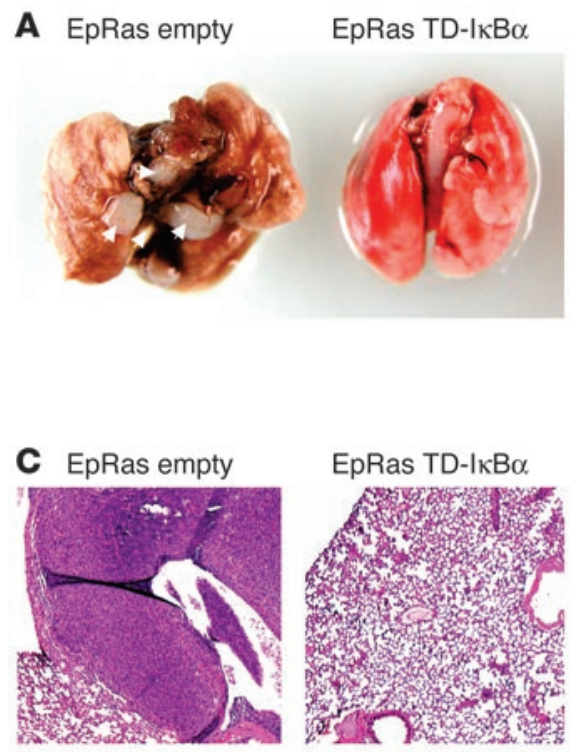

Figure 9

Inhibition of NF- $\kappa$ B activity prevents metastasis of EpRas cells. (A) EpRas cells infected with empty GFP vector (Empty) or TD-IкB $\alpha$ were injected $\left(5 \times 10^{5}\right.$ cells per injection) into the tail veins of nude mice (four animals per cell type), and mice were analyzed for the presence of lung metastases. Note large metastatic nodules (white arrows) in the lung from the mouse injected with EpRas cells that had been infected with empty vector (EpRas empty; left). (B) Metastases in lungs similar to those shown in A were quantified in serial sections to determine the mean numbers of metastases per lung (four lungs per cell type). (C) Hematoxylin and eosin staining of lungs from mice injected with EpRas cells that had been infected with empty vector or TD-I $\mathrm{KB} \alpha$. Note large metastases in the mouse injected with EpRas cells that had been infected with empty vector. Original magnification, $\times 10$. (D) The same cells analyzed in A-C were injected $\left(2 \times 10^{5}\right.$ cells per injection site; four injection sites per animal) into the fat pads of nude mice (three animals per cell type), and total tumor weight was determined for each individual mouse after 3 weeks. Average total tumor weights are shown.

mainly in size (Figure 9D). In conclusion, inhibition of NF- $\mathrm{KB}$ activity strongly affects the metastatic potential of EpRas cells in vivo, while primary tumor formation is affected only moderately.

\section{Discussion}

Activation of NF- $\mathrm{KB}$ signaling is increasingly being recognized as a key mechanism for tumorigenesis and is thought to act mainly by conferring apoptosis resistance to transformed cells. In this report, we used a well characterized combined in vitro/in vivo model of mammary carcinogenesis (EpRas) to determine the function of $\mathrm{NF}-\mathrm{\kappa B}$ in the regulation of epithelial plasticity and metastasis. First, we showed that NF-KB activity is required together with oncogenic Ras for efficient protection of mammary epithelial cells from TGF- $\beta$ induced apoptosis, as a prerequisite for these cells to undergo an EMT toward an invasive, metastatic tumor phenotype. Second, NF-кB can, in part, induce EMT in Ras-transformed cells in the absence of TGF- $\beta$, suggesting that NF- $\mathrm{KB}$ signaling can mediate important aspects of TGF- $\beta$ signaling essential for inducing EMT. Third, NF- $\mathrm{KB}$ activity is necessary for cells to be maintained in a mesenchymal state, as its inhibition causes reversal of EMT; and finally, in agreement with its essential role in the regulation of at least these three distinct aspects of tumor progression in vitro, NF- $\mathrm{KB}$ signaling is required for metastasis of Ras-transformed epithelial cells in vivo.
$N F-\kappa B$ is required for distinct aspects of tumor progression. Our observation that the antiapoptotic role of NF- $\mathrm{\kappa B}$ plays a critical role in late-stage tumorigenesis (EMT) is consistent with many reports in the literature. Indeed, NF- $\mathrm{KB}$ positively regulates a plethora of antiapoptotic genes (30), and constitutive NF-KB activity has been found in breast, prostate, colorectal, and ovarian cancers and in certain forms of leukemia and lymphoma (reviewed in ref. 2). Inhibition of NF- $\mathrm{kB}$ in many human tumor-derived cell lines, including malignant Reed-Sternberg cells of Hodgkin disease, induces spontaneous apoptosis and/ or sensitizes cells to killing by TNF- $\alpha$ or anticancer drugs (30). Several studies have demonstrated that inhibition of NF- $\mathrm{kB}$ results in an increased sensitivity of tumor cells to cancer therapy-induced apoptosis. For example, delivery of a recombinant TD-IкB $\alpha$ to chemoresistant tumors in mouse xenograft models induced tumor regression by sensitizing them to chemotherapeutic treatment with the topoisomerase I inhibitor CPT-11 $(31,32)$. Our results clearly establish a critical role for NF-KB as an important regulator of the EMT gene program that goes beyond its well established function in apoptosis protection. This is based on several lines of evidence. First, NF-KB activation is sufficient to induce EMT in a considerable proportion of epithelial EpRas cells. Second, NF-кB inhibition results in a blockade of EMT (under conditions in which apoptosis was efficiently suppressed). Third, NF-kB is a critical factor for the activation of a subset of endogenous genes in the TGF- $\beta$ induced gene program. Finally, NF- $\mathrm{kB}$ blockade can partially revert EMT, resulting in viable and healthy epithelial cells.

Here we demonstrate for the first time to our knowledge that NF-KB plays a causal role in the induction and maintenance of EMT in Ras-transformed mammary epithelial cells, mediating an invasive/metastatic tumor phenotype. These findings add mechanistic insight regarding the role of NF-KB in late-stage mammary tumorigenesis and metastasis. Our observations regarding a detectable or further elevated baseline activity of NF-kB in unstimulated EpRas and EpRasXT cells, respectively, are consistent with reports demonstrating constitutive activation of NF- $\mathrm{KB}$ factors in breast cancer $(33,34)$. Inhibition of the constitutive NF- $\mathrm{kB}$ activity in human breast cancer cell lines induced apoptosis (34) or led to reduced tumorigenicity (35). Furthermore, mouse mammary tumor virus $c$-rel-transgenic mice develop late-onset mammary tumors of diverse histology (36). Interestingly, some of the tumors identified in the study by Romieu-Mourez et al. were spindle cell carcinomas, a tumor type possibly generated by $\operatorname{EMT}(12,22)$.

Recent studies have suggested that NF- $\mathrm{KB}$ regulates the expression of multiple genes involved in tumor spread and metastasis, including those encoding MMPs, IL-8, VEGF, and CXCR4 $(37,38)$. Several NF-kB target genes we have reported to be induced during EMT of EpRas cells, such as those encoding various MMPs and cathepsin family members, chemokines/cytokines, tenascin-C, etc. (see Table 1 and Figure 3E), could contribute to the NF-KBdependent metastatic capacity we observed in our study. Suppression of metastasis upon blockade of NF-kB activity has also been reported in human prostate cancer cells (37), in human melanoma cells (39), and in murine lung alveolar carcinoma cells (40). Collectively, our work and work by others clearly show the importance of NF- $\mathrm{kB}$ signaling for tumor progression and metastasis in multiple tumor model systems. It should be noted, however, that while NF- $\mathrm{kB}$ contributes to oncogenesis in many cell types, its I $\mathrm{B} \alpha \alpha$-mediated suppression in keratinocytes was recently dem- 
onstrated to be necessary for Ras-mediated induction of invasive epidermal tumors resembling squamous cell carcinomas (41). The role of TGF- $\beta$ signaling in the oncogenic Ras/IкB $\alpha$ tumors, however, has not been addressed.

Role of NF-кB in the cooperation of Ras- and TGF- $\beta$-dependent signaling pathways during tumor progression. Previous studies by Janda et al. (17) addressed the effect of Ras signaling pathways on epithelial plasticity in the EpH4/EpRas model, using Ras mutants that specifically activate only the Raf/MEK/Erk pathway (S35Ras) or the PI3K/Akt pathway (C40Ras). Furthermore, specific inhibitors that block Ras, MEK1, or PI3K were used to interfere with EMT induction or maintenance in EpRas cells (17). Both approaches showed that Ras-dependent signaling of the Raf/MEK/Erk pathway in combination with TGF- $\beta$ signaling is required for EMT (17). In contrast, C40-induced PI3K/Akt signaling protected EpH4 cells from TGF- $\beta$-induced apoptosis, but failed to induce EMT. In vivo, only a Ras mutant able to activate the Raf/MEK/Erk pathway (S35Ras), but not the C40Ras mutant, was able to generate metastases, strictly correlating with the potential of these mutants to induce EMT (17). A number of reports have shown that oncogenic Ras stimulates NF- $\mathrm{KB}$-dependent transcription and that NF- $\mathrm{KB}$ is required for Ras-mediated transformation (reviewed in ref. 1). Several lines of evidence indicate that NF-кB acts in a common pathway with PI3K/Akt, leading to suppression of TGF- $\beta$-induced apoptosis in Ras-transformed mammary epithelial cells. First, the rate of TGF- $\beta$-dependent apoptosis induction is very similar in TD-IкB $\alpha$-expressing EpRas cells and in EpRas cells treated with a specific PI3K inhibitor (17). Second, Akt has been shown in several cellular systems to stimulate signaling pathways that upregulate the activity of NF-кB. Importantly, the antiapoptotic signals elicited by PDGF have been shown to require Akt-induced NF- $\kappa B$ transcriptional activity (42). Several reports have indicated that IKK activity is involved in the ability of Akt to stimulate NF- $\mathrm{B}$ transcriptional activity (42-44), while others have found that PI3K or Akt can also stimulate NF- $\mathrm{BB}$ activity through signaling pathways targeting the $\mathrm{p} 65$ subunit of NF- $\mathrm{KB}$ (45). Our finding that modulating NF- $\mathrm{\kappa B}$ activity has the same effects in EpRas cells and V12S35 cells would be consistent with the interpretation that the PI3K/Akt signaling may be upstream of NF- $\kappa \mathrm{B}$ activity. Collectively, further experiments are required to elucidate how NF-KB precisely mediates Ras-dependent effects in the EpRas cellular system.

Our observation that TGF- $\beta$-dependent induction of EMT depends at least in part on NF- $\mathrm{KB}$ activity raises the question of how these signaling pathways may collaborate. Induction of NF- $\mathrm{BB}$ activity and transcription of target genes by TGF- $\beta$, as observed in our study, are in line with observations by Arsura et al. (28) in liver epithelial cells. TGF- $\beta$ can signal in a Smad-independent manner through TGF- $\beta 1$-activated kinase 1 (TAK1). Interestingly, TAK1 has been shown to directly phosphorylate the IKK complex in response to TGF- $\beta$ treatment, promoting NF- $\kappa$ B activation (28). In addition, several Smad proteins, acting as transcription factors defined as the major responders to TGF- $\beta$ signaling, can function as transcriptional coactivators through physical interaction with $\mathrm{NF}-\kappa \mathrm{B}$ subunits to stimulate transcription via $\kappa \mathrm{B}$ sites (46). It will be important to further analyze at which levels these two pathways intersect to abrogate the classical functions of TGF- $\beta$ in the induction of apoptosis and how they cooperate in enhancing the role of TGF- $\beta$ in the induction of EMT. A potential novel point of intersection has been discovered very recently. TGF- $\beta$ induces transcrip- tion of the cell cycle inhibitor p21CIP1 by a mechanism, in which Smad proteins cooperate with FoxO transcription factors (47). Three strategies have been described to overcome this cell cycle inhibition. The first is counteraction of FoxO function by another member of the Fox transcription factor family, namely FoxG1 (47). The second is inactivation of FoxO proteins by the PI3K/Akt pathway, which results in relocalization of FoxO proteins to the cytoplasm (48). Third, in breast tumors, upregulation of IKK-2 has been observed and IKK-2 was shown to directly phosphorylate and functionally inactivate the FoxO proteins (49).

In summary, our study provides a functional dissection of the requirement for NF- $\mathrm{KB}$ in several aspects of breast cancer progression in this combined in vitro/in vivo model system. It identifies NF-KB as a pivotal regulator of the EMT process, which by itself is a critical prerequisite for metastasis. Further characterization of the mechanisms by which NF- $\mathrm{BB}$ contributes to the invasion and metastasis of mammary carcinomas and other malignant tumors will provide important targets for drug discovery, which should lead to new therapeutic approaches for antimetastatic cancer treatments.

\section{Methods}

Cells and cell culture. Origin and culture conditions for EpRas and EpRasXT cells were described earlier $(19,20)$. The generation and culture conditions of $\phi N X$ amphotropic retrovirus producer cells expressing TD-IKB $\alpha, C A-I K K-2$, and parental vector, coupled to the expression of a GFP-zeocin-resistance fusion gene through an internal ribosome entry site were described previously (29).

Retroviral infection of EpRas and EpRasXT cells with supernatant from $\phi N X$ producer cells. EpRas and EpRasXT cells were infected with parental vector or retroviruses expressing the dominant interfering mutants as described earlier (29). Briefly, 24 hours prior to infection, EpRas and EpRasXT cells were seeded in six-well plates at a density of $2 \times 10^{5}$ cells per well, and $\phi \mathrm{NX}$ cells were seeded at a density of $3 \times 10^{6}$ cells per $10-\mathrm{cm}$ plate. For infection, $\phi N X$ cell supernatants were obtained and filtered through a 0.45 $\mu \mathrm{m}$ filter, and $5 \mu \mathrm{g} / \mathrm{ml}$ polybrene (Sigma-Aldrich, St. Louis, Missouri, USA) was added to the filtrate. Thereafter, medium was removed from the EpRas and EpRasXT cells and was replaced with $\phi N X$ cell supernatants containing the retrovirus. Culture plates were centrifuged at $750 \mathrm{~g}$ for 2 hours, the supernatants were removed and replaced with propagation medium. Then, 48 hours later, the efficiency of infection was monitored by fluorescence microscopy (Improvision, Heidelberg, Germany) and infected cells were selected with zeocin at concentrations of 1,500 $\mu \mathrm{g} / \mathrm{ml}$ (EpRas) and $1,700 \mu \mathrm{g} / \mathrm{ml}$ (EpRasXT).

$N F-\kappa B$ assays. Western immunoblot analysis for monitoring protein expression levels of dominant interfering NF-kB mutants was performed as described earlier (29) using antibodies specific for ІкB $\alpha$ (sc-371; Santa Cruz Biotechnology, Santa Cruz, California, USA), IKK-2 (sc-7607; Santa Cruz Biotechnology), and RelA (sc-372; Santa Cruz Biotechnology).

NF-кB DNA-binding activity was measured by EMSA. Whole-cell extracts were prepared by the "freeze-thaw" method and EMSAs were performed as described earlier (29). In all cases, whole-cell extracts were incubated for 20 minutes at room temperature with radiolabeled doublestranded oligonucleotides containing an Igא enhancer consensus NF- $\mathrm{B}$ site, an octamer-specific site ( $5^{\prime}$-ATGCAAAT- $\left.3^{\prime}\right)$, or an Sp-1-specific site (5'-ATTCGATCGGGGCGGGGCGAGC-3'), and the DNA-protein complexes formed were then separated from free oligonucleotides by electrophoresis through a native $4 \%$ polyacrylamide gel.

Modulations of NF-אB transactivation activity were measured by stable transfection of EpRas and EpRasXT parental and retrovirus-transduced 
clones with the $3 \times \kappa \mathrm{B}$ luciferase reporter (3хкB.luc) and $\beta$-globin-TATA, and subsequent luciferase activity assays. In brief, cells were transfected with $10 \mu \mathrm{g}$ of the 3 хкB.luc reporter plasmid together with $100 \mathrm{ng}$ of a thymidine kinase Renilla luciferase reporter under the control of the herpes simplex virus thymidine kinase promoter. Transfections were performed by incubation of cells for 4 hours with a mixture of DNA and lipofectamine at a ratio of 1:2.5 (Lipofectamine 2000; Invitrogen, Carlsbad, California, USA) in serum-free media. At 20-28 hours after the start of transfection, luciferase activity was determined with the Lumat LB 9507 luminometer (Berthold Technologies, Bad Wildbad, Germany).

Semiquantitative RT-PCR. Total RNA was extracted and semiquantitative RT-PCR was carried out as described earlier (29). Mouse MMP-13 was amplified with primers $5^{\prime}$-CACTCCAAGGACCCAGGAGCCC-3' (sense) and 5'-GCTGAGGGTGCAGGCGCCAGAA-3' (antisense; 28 cycles); mouse MCP-1 was amplified with primers 5'-CGGCTGGAGCATCCACGTGTTG$3^{\prime}$ (sense) and 5'-GTCTGGACCCATTCCTTCTTGGGG-3' (antisense; 28 cycles); mouse cholecystokinin was amplified with primers 5'-CGCAGCCGGTAGTCCCTGCAGAA-3' (sense) and 5'-CCATCCAGCCCATGTAGTCCCGG-3' (antisense; 28 cycles); and mouse $\beta$-actin was amplified with primers 5'-GGTCAGAAGGACTCCTATGTG-3' (sense) and 5'-AGAGCAACATAGCACAGCTTC-3' (antisense; 28 cycles).

Marker analysis of cells grown on porous support. Cells were seeded on porous supports (cell culture inserts; pore size, $0.4 \mu \mathrm{m}$; BD, San Jose, California, USA) at densities of $0.5 \times 10^{5}$ cells/well for EpRas cells and 1 $\times 10^{5}$ cells/well for EpRasXT cells. In some experiments, cells were incubated with the indicated concentration (see Figure 6C) of the broadrange caspase inhibitor Z-VAD-FMK (R\&D Systems, Minneapolis, Minnesota, USA). Fresh inhibitor was supplied with each medium change every other day. Cells were cultivated for 5-7 days and then either cells were subjected to immunofluorescence staining (described in detail in ref. 17) with polyclonal rabbit anti-E-cadherin (610182; 1:500 dilution; BD), monoclonal anti-mouse vimentin (Vim-13.4; V-2258; 1:500 dilution; Sigma-Aldrich), and Cy3-conjugated donkey anti-mouse IgG as secondary antibody (1:1,000 dilution; Jackson ImmunoResearch Laboratories), or cells were lysed in buffer containing $20 \mathrm{mM}$ HEPES, $25 \%$ glycerol, $0.42 \mathrm{M} \mathrm{NaCl}, 1.5 \mathrm{mM} \mathrm{MgCl}_{2}$, and $0.2 \mathrm{mM}$ EDTA and subjected to Western immunoblot analysis with antibodies specific for E-cadherin, vimentin, and RelA (as specified above). For immunofluorescence staining, DAPI $(0.1 \mathrm{ng} / \mathrm{ml})$ was used for nuclear counterstaining. Digital images were collected either with a MicroMAX camera (Roper Scientific, Trenton, New Jersey, USA) on a Zeiss Axioplan 2 (Zeiss, Thornwood, New York, USA) using Metamorph software (EpRas cells; Universal Imaging Corp., Philadelphia, Pennsylvania, USA), or on a fluorescence microscope (Improvision) using OpenLab 3.0.2 and 3.0.3 software (EpRasXT cells; Improvision).

Collagen gel culture, marker analysis, and apoptosis assay. Serum-free, three-dimensional cultures of EpRas cells and their derivatives were performed as described earlier $(17,19)$. TGF- $\beta 1$ (5 ng/ml; R\&D Systems) was added to the cultures after 2-5 days and then was supplied together with fresh medium every other day for a total of 5-7 days. In situ immunofluorescence analysis was performed to analyze three-dimensional structures for E-cadherin and vimentin expression, as described by Janda et al. (17). The following antibodies were used: polyclonal rabbit anti-E-cadherin (610182; 1:500 dilution; BD), monoclonal anti-mouse vimentin (Vim-13.4; V-2258; 1:500 dilution; Sigma-Aldrich), and Cy3conjugated goat anti-mouse IgG as secondary antibody (1:3,000 dilution; Jackson ImmunoResearch Laboratories). In all cases, DAPI $(0.1 \mathrm{ng} / \mathrm{ml})$ was used for nuclear counterstaining.

For TUNEL assays, collagen gels were fixed in $4 \%$ paraformaldehyde in PBS, washed with PBS three times, and stained for apoptotic nuclei with the In Situ Cell Death Detection Kit, TMR red (2156792; Roche Diagnostics, Indianapolis, Indiana, USA), according to the manufacturer's instructions. DAPI $(0.1 \mathrm{ng} / \mathrm{ml})$ was used for nuclear counterstaining.

Digital images of immunofluorescence-stained and TUNEL-stained collagen gels were collected with a MicroMAX camera on a Zeiss Axioplan 2 using Micromorph software. For quantification of the TUNEL assay, more than 300 cells from at least three fields in each collagen gel were counted and average apoptotic indices were determined from two collagen gels.

Annexin $V$ staining. XT cells expressing either TD-IкB $\alpha$ or the empty vector were grown for 4 days on cell culture inserts with a pore size of 0.4 $\mu \mathrm{m}$ (BD). Cells were scraped off the filters, washed twice in ice-cold PBS, and resuspended in binding buffer (BD) at a density of $1 \times 10^{6}$ cells $/ \mathrm{ml}$. Then, $1 \times 10^{5}$ cells were stained with $5 \mu$ l of phycoerythrin-conjugated annexin $\mathrm{V}(\mathrm{BD})$ for 15 minutes, washed twice with PBS, and analyzed by flow cytometry (FACSCalibur, BD).

Tumorigenesis and metastasis assays. All animal studies have been approved by the review board of the Institute of Molecular Pathology. Athymic MF1 nude mice were used for mammary gland and tail vein injections, with 200,000 cells per $20 \mu \mathrm{l}$ PBS for mammary gland injection (tumorigenesis assay) and 500,000 cells per $0.5 \mathrm{ml}$ PBS for tail vein injection (metastasis assay) of 6- to 10-week-old female mice.

For tumorigenesis assays, mice were sacrificed when tumors of control animals had reached a size of approximately $1.0-1.5 \mathrm{~cm}$ in diameter (on average, 3 weeks after mammary gland injection) or if tumors ulcerated or the mice showed significant morbidity. Then, tumors were excised and collected in PBS and total tumor weight (from four injection sites per mouse) was determined for each individual animal.

For metastasis assays, mice were checked daily for weight loss and breathlessness for detection of massive lung metastasis. The mice of an entire experiment were sacrificed at the time when control mice started to die from lung metastasis (on average, 3-4 weeks after tail vein injection). Lungs were excised and collected in PBS, and lung weight was determined.

For histological analysis of metastasis assays, lungs were immersed in $10 \%$ neutral buffered formalin before paraffin embedding and sectioning. Sections $5 \mu \mathrm{m}$ in thickness were processed for hematoxylin and eosin staining and histological evaluation. Total numbers of metastases per lung were determined by collection of serial lung sections, selection of sections at approximately $0.3 \mathrm{~mm}$ apart, and counting of metastatic lesions, with correction for the contribution of large metastatic lesions that appeared on more than one section.

\section{Acknowledgments}

We are grateful to M. Jechlinger for providing EpRas and EpRasXT cells; B. Anic and G. Litos for excellent technical assistance; K. Stangl and P. Garin-Chesa for help with histology; the Institute of Molecular Pathology BioOptics Department for support with immunofluorescence microscopy; and K. Scharffetter-Kochanek, P. Petzlbauer, C. Hoeller, S. Maschler, and M. Herlyn for scientific discussions and useful comments. This work was in part funded by the Genome Research in Austria (GEN-AU) program (to M.A. Huber) and by the German Science Foundation (DFG SFB497/B1 to B. Baumann; SFB451/A9 to T. Wirth).

Received for publication February 17, 2004, and accepted in revised form June 22, 2004.

Address correspondence to: Thomas Wirth, Department of Physiological Chemistry, Ulm University, Albert-Einstein-Allee 11, D-89081 Ulm, Germany. Phone: 49-731-500-23270; Fax: 49-731-500-22892; E-mail: thomas.wirth@medizin.uni-ulm.de. 
1. Orlowski, R.Z., and Baldwin, A.S., Jr. 2002. NF-кB as a therapeutic target in cancer. Trends Mol. Med. 8:385-389.

2. Karin, M., Cao, Y., Greten, F.R., and Li, Z.W. 2002. NF- $\kappa \mathrm{B}$ in cancer: from innocent bystander to major culprit. Nat. Rev. Cancer. 2:301-310.

3. Ghosh, S., May, M.J., and Kopp, E.B. 1998. NF-кB and Rel proteins: evolutionarily conserved mediators of immune responses. Annu. Rev. Immunol. 16:225-260.

4. Karin, M., and Ben-Neriah, Y. 2000. Phosphorylation meets ubiquitination: the control of NF- $\mathrm{KB}$ activity. Annu. Rev. Immunol. 18:621-663.

5. Gilmore, T.D. 1999. Multiple mutations contribute to the oncogenicity of the retroviral oncoprotein v-Rel. Oncogene. 18:6925-6937.

6. Cahir-McFarland, E.D., Izumi, K.M., and Mosialos, G. 1999. Epstein-Barr virus transformation: involvement of latent membrane protein 1-mediated activation of NF-кB. Oncogene. 18:6959-6964.

7. Sun, S.C. and Ballard, D.W. 1999. Persistent activation of NF- $\kappa \mathrm{B}$ by the tax transforming protein of HTLV-1: hijacking cellular IкB kinases. Oncogene. 18:6948-6958.

8. Rayet, B., and Gelinas, C. 1999. Aberrant rel/nfkb genes and activity in human cancer. Oncogene. 18:6938-6947.

9. Bargou, R.C., et al. 1997. Constitutive nuclear factor- $\mathrm{KB}$-RelA activation is required for proliferation and survival of Hodgkin's disease tumor cells. J. Clin. Invest. 100:2961-2969.

10. Cabannes, E., Khan, G., Aillet, F., Jarrett, R.F., and Hay, R.T. 1999. Mutations in the $I \kappa B \alpha$ gene in Hodgkin's disease suggest a tumour suppressor

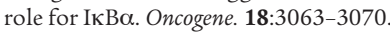

11. Boyer, B., Valles, A.M., and Edme, N. 2000. Induction and regulation of epithelial-mesenchymal transitions. Biochem. Pharmacol. 60:1091-1099.

12. Thiery,J.P. 2002. Epithelial-mesenchymal transitions in tumour progression. Nat. Rev. Cancer. 2:442-454.

13. Thiery, J.P. 2003. Epithelial-mesenchymal transitions in development and pathologies. Curr. Opin. Cell Biol. 15:740-746.

14. Petersen, O.W., et al. 2003. Epithelial to mesenchymal transition in human breast cancer can provide a nonmalignant stroma. Am. J. Pathol. 162:391-402.

15. Grünert, S., Jechlinger, M., and Beug, H. 2003. Diverse cellular and molecular mechanisms contribute to epithelial plasticity and metastasis. Nat. Rev. Mol. Cell Biol. 4:657-665.

16. Hay, E.D. 1995. An overview of epithelio-mesenchymal transformation. Acta Anat. (Basel). 154:8-20.

17. Janda, E., et al. 2002. Ras and TGF $\beta$ cooperatively regulate epithelial cell plasticity and metastasis: dissection of Ras signaling pathways. J. Cell Biol. 156:299-313.

18. Jechlinger, M., et al. 2003. Expression profiling of epithelial plasticity in tumor progression. Oncogene. 22:7155-7169.

19. Oft, M., et al. 1996 . TGF- $\beta 1$ and Ha-Ras collaborate in modulating the phenotypic plasticity and invasiveness of epithelial tumor cells. Genes Dev. 10:2462-2477.

20. Oft, M., Heider, K.H., and Beug, H. 1998. TGF $\beta$ signaling is necessary for carcinoma cell invasiveness and metastasis. Curr. Biol. 8:1243-1252.

21. Lehmann, K., et al. 2000. Raf induces TGF $\beta$ production while blocking its apoptotic but not invasive responses: a mechanism leading to increased malignancy in epithelial cells. Genes Dev. 14:2610-2622.

22. Oft, M., Akhurst, R.J., and Balmain, A. 2002. Metastasis is driven by sequential elevation of $\mathrm{H}$-ras and Smad2 levels. Nat. Cell Biol. 4:487-494.

23. Gotzmann, J., et al. 2002. Hepatocytes convert to a fibroblastoid phenotype through the cooperation of TGF- $\beta 1$ and Ha-Ras: steps towards invasiveness. J. Cell. Sci. 115:1189-1202.

24. Dechend, R., et al. 1999. The Bcl-3 oncoprotein acts as a bridging factor between NF- $\mathrm{B} / \mathrm{Rel}$ and nuclear co-regulators. Oncogene. 18:3316-3323.

25. Cogswell, P.C., Guttridge, D.C., Funkhouser, W.K., and Baldwin, A.S., Jr. 2000. Selective activation of NF-кB subunits in human breast cancer: potential roles for NF-кB2/p52 and for Bcl-3. Oncogene. 19:1123-1131.

26. Adolph, K.W., Liska, D.J., and Bornstein, P. 1997. Analysis of the promoter and transcription start sites of the human thrombospondin 2 gene (THBS2). Gene. 193:5-11.

27. Pahl, H.L. 1999. Activators and target genes of Rel/NF-кB transcription factors. Oncogene. 18:6853-6866.

28. Arsura, M., et al. 2003. Transient activation of NF- $\kappa \mathrm{B}$ through a TAK1/IKK kinase pathway by TGF- $\beta 1$ inhibits AP- 1 /SMAD signaling and apoptosis: implications in liver tumor formation. Oncogene. 22:412-425.

29. Huber, M.A., et al. 2002. The IKK-2/IкB $\alpha /$ $\mathrm{NF}-\kappa \mathrm{B}$ pathway plays a key role in the regulation of CCR3 and eotaxin-1 in fibroblasts. A critical link to dermatitis in IкB $\alpha$-deficient mice. J. Biol. Chem. 277:1268-1275.

30. Kucharczak, J., Simmons, M.J., Fan, Y., and Gelinas, C. 2003. To be, or not to be: NF-KB is the answerrole of Rel/NF- $\kappa \mathrm{B}$ in the regulation of apoptosis. Oncogene. 22:8961-8982.

31. Wang, C.Y, Cusack, J.C., Jr., Liu, R., and Baldwin, A.S., Jr. 1999. Control of inducible chemo-resistance: enhanced anti-tumor therapy through increased apoptosis by inhibition of NF- $\kappa$ B. Nat. Med. 5:412-417.

32. Cusack, J.C., Jr., Liu, R., and Baldwin, A.S., Jr. 2000. Inducible chemoresistance to 7-ethyl-10-[4-(1piperidino)-1-piperidino]-carbonyloxycamptothecin (CPT-11) in colorectal cancer cells and a xenograft model is overcome by inhibition of nuclear factor- $\kappa \mathrm{B}$ activation. Cancer Res. 60:2323-2330.

33. Nakshatri, H., Bhat-Nakshatri, P., Martin, D.A., Goulet, R.J., Jr., and Sledge, G.W., Jr. 1997. Constitutive activation of NF- $\mathrm{KB}$ during progression of breast cancer to hormone-independent growth. Mol. Cell. Biol. 17:3629-3639.

34. Sovak, M.A., et al. 1997. Aberrant nuclear factor$\mathrm{\kappa B} /$ Rel expression and the pathogenesis of breast cancer. J. Clin. Invest. 100:2952-2960.

35. Romieu-Mourez, R., et al. 2001. Roles of IKK kinases and protein kinase CK2 in activation of nuclear factor- $\mathrm{KB}$ in breast cancer. Cancer Res. 61:3810-3818.

36. Romieu-Mourez, R., et al. 2003. Mouse mammary tumor virus c-rel transgenic mice develop mammary tumors. Mol. Cell. Biol. 23:5738-5754.

37. Huang, S., Pettaway, C.A., Uehara, H., Bucana, C.D., and Fidler, I.J. 2001. Blockade of NF- $\mathrm{\kappa B}$ activity in human prostate cancer cells is associated with suppression of angiogenesis, invasion, and metastasis. Oncogene. 20:4188-4197.

38. Helbig, G., et al. 2003. NF-кB promotes breast cancer cell migration and metastasis by inducing the expression of the chemokine receptor CXCR4. J. Biol. Chem. 278:21631-21638

39. Huang, S., DeGuzman, A., Bucana, C.D., and Fidler, I.J. 2000. Nuclear factor- $\kappa \mathrm{B}$ activity correlates with growth, angiogenesis, and metastasis of human melanoma cells in nude mice. Clin. Cancer Res. 6:2573-2581.

40. Andela, V.B., Schwarz, E.M., Puzas, J.E., O’Keefe, R.J., and Rosier, R.N. 2000. Tumor metastasis and the reciprocal regulation of prometastatic and antimetastatic factors by nuclear factor kappa B. Cancer Res. 60:6557-6562.

41. Dajee, M., et al. 2003. NF-кB blockade and oncogenic Ras trigger invasive human epidermal neoplasia. Nature. 421:639-643.

42. Romashkova, J.A., and Makarov, S.S. 1999. NF-кB is a target of AKT in anti-apoptotic PDGF signalling. Nature. 401:86-90.
43. Kane, L.P., Shapiro, V.S., Stokoe, D., and Weiss, A. 1999. Induction of NF-KB by the Akt/PKB kinase. Curr. Biol. 9:601-604.

44. Ozes, O.N., et al. 1999. NF-кB activation by tumour necrosis factor requires the Akt serine-threonine kinase. Nature. 401:82-85.

45. Madrid, L.V., Mayo, M.W., Reuther, J.Y., and Baldwin, A.S., Jr. 2001. Akt stimulates the transactivation potential of the RelA/p65 Subunit of NF- $\kappa \mathrm{B}$ through utilization of the IкB kinase and activation of the mitogen-activated protein kinase p38. J. Biol. Chem. 276:18934-18940.

46. Lopez-Rovira, T., Chalaux, E., Rosa, J.L., Bartrons, R., and Ventura, F. 2000. Interaction and functional cooperation of NF- $\kappa \mathrm{B}$ with Smads. Transcriptional regulation of the junB promoter. J. Biol. Chem. 275:28937-28946.

47. Seoane, J., Le, H.-V., Shen, L., Anderson, S.A., and Massague, J. 2004. Integration of Smad and forkhead pathways in the control of neuroepithelial and glioblastoma cell proliferation. Cell. 117:211-223.

48. Brunet, A., et al. 1999. Akt promotes cell survival by phosphorylating and inhibiting a forkhead transcription factor. Cell. 96:857-868.

49. Hu, M.C.-T., et al. 2004. IкB kinase promotes tumorigenesis through inhibition of forkhead FoxO3a. Cell. 117:225-237.

50. Lilienbaum, A., Duc Dodon, M., Alexandre, C., Gazzolo, L., and Paulin, D. 1990. Effect of human Tcell leukemia virus type I tax protein on activation of the human vimentin gene. J. Virol. 64:256-263.

51. Li, X., et al. 2002. IKK $\alpha$, IKK $\beta$, and NEMO/IKK $\gamma$ are each required for the NF- $\mathrm{KB}-$ mediated inflammatory response program. J. Biol. Chem. 277:45129-45140.

52. Katsel, P.L., and Greenstein, R.J. 2001. Identification of overlapping AP-2/NF-KB-responsive elements on the rat cholecystokinin gene promoter. J. Biol. Chem. 276:752-758.

53. Ueda, A., et al. 1994. NF-кB and Sp1 regulate transcription of the human monocyte chemoattractant protein-1 gene. J. Immunol. 153:2052-2063.

54. Liacini, A., et al. 2003. Induction of matrix metalloproteinase- 13 gene expression by TNF- $\alpha$ is mediated by MAP kinases, AP-1, and NF- $\mathrm{KB}$ transcription factors in articular chondrocytes. Exp. Cell Res. 288:208-217.

55. Mettouchi, A., et al. 1997. The c-Jun-induced transformation process involves complex regulation of tenascin-C expression. Mol. Cell. Biol. 17:3202-3209.

56. Tian, B., and Brasier, A.R. 2003. Identification of a nuclear factor $\kappa \mathrm{B}$-dependent gene network. Recent Prog. Horm. Res. 58:95-130.

57. Philip, S., Bulbule, A., and Kundou, G.C. 2001. Osteopontin stimulates tumor growth and activation of promatrix metalloproteinase- 2 through nuclear factor- $\mathrm{\kappa B}$-mediated induction of membrane type 1 matrix metalloproteinase in murine melanoma cells. J. Biol. Chem. 276:44926-44935.

58. Israel, A., et al. 1989. TNF stimulates expression of mouse MHC class I genes by inducing an NF-кB-like enhancer binding activity which displaces constitutive factors. EMBO J. 8:3793-3800.

59. Israel, A., Yano, O., Logeat, F., Kieran, M., and Kourilsky, P. 1989. Two purified factors bind to the same sequence in the enhancer of mouse MHC class I genes: one of them is a positive regulator induced upon differentiation of teratocarcinoma cells. Nucleic Acids Res. 17:5245-5257.

60. Bitko, V., Velazquez, A., Yang, L., Yang, Y.C., and Barik, S. 1997. Transcriptional induction of multiple cytokines by human respiratory syncytial virus requires activation of NF-KB and is inhibited by sodium salicylate and aspirin. Virology. 232:369-378.

61. Ohmori, Y., Fukumoto, S., and Hamilton, T.A 1995. Two structurally distinct kappa B sequence motifs cooperatively control LPS-induced KC gene transcription in mouse macrophages. J. Immunol. 155:3593-3600. 